\title{
Nr4a1-eGFP Is a Marker of Striosome-Matrix Architecture, Development and Activity in the Extended Striatum
}

\author{
Margaret I. Davis ${ }^{1 *}$, Henry L. Puhl III ${ }^{2}$ \\ 1 Laboratory for Integrative Neuroscience, National Institute on Alcohol Abuse and Alcoholism, National Institutes of Health, Bethesda, Maryland, United States of \\ America, $\mathbf{2}$ Laboratory of Molecular Physiology, National Institute on Alcohol Abuse and Alcoholism, National Institutes of Health, Bethesda, Maryland, United States of \\ America
}

\begin{abstract}
Transgenic mice expressing eGFP under population specific promoters are widely used in neuroscience to identify specific subsets of neurons in situ and as sensors of neuronal activity in vivo. Mice expressing eGFP from a bacterial artificial chromosome under the Nr4a1 promoter have high expression within the basal ganglia, particularly within the striosome compartments and striatal-like regions of the extended amygdala (bed nucleus of the stria terminalis, striatal fundus, central amygdaloid nucleus and intercalated cells). Grossly, eGFP expression is inverse to the matrix marker calbindin $28 \mathrm{~K}$ and overlaps with mu-opioid receptor immunoreactivity in the striatum. This pattern of expression is similar to Drd1, but not Drd2, dopamine receptor driven eGFP expression in structures targeted by medium spiny neuron afferents. Striosomal expression is strong developmentally where Nr4a1-eGFP expression overlaps with Drd1, TrkB, tyrosine hydroxylase and phospho-ERK, but not phospho-CREB, immunoreactivity in "dopamine islands". Exposure of adolescent mice to methylphenidate resulted in an increase in eGFP in both compartments in the dorsolateral striatum but eGFP expression remained brighter in the striosomes. To address the role of activity in Nr4a1-eGFP expression, primary striatal cultures were prepared from neonatal mice and treated with forskolin, BDNF, SKF-83822 or high extracellular potassium and eGFP was measured fluorometrically in lysates. eGFP was induced in both neurons and contaminating glia in response to forskolin but SKF-83822, brain derived neurotrophic factor and depolarization increased eGFP in neuronal-like cells selectively. High levels of eGFP were primarily associated with Drd1+ neurons in vitro detected by immunofluorescence; however $\sim 15 \%$ of the brightly expressing cells contained punctate met-enkephalin immunoreactivity. The Nr4a1-GFP mouse strain will be a useful model for examining the connectivity, physiology, activity and development of the striosome system.
\end{abstract}

Citation: Davis MI, Puhl HL III (2011) Nr4a1-eGFP Is a Marker of Striosome-Matrix Architecture, Development and Activity in the Extended Striatum. PLoS ONE 6(1): e16619. doi:10.1371/journal.pone.0016619

Editor: Maria Deli, Biological Research Center of the Hungarian Academy of Sciences, Hungary

Received August 24, 2010; Accepted January 7, 2011; Published January 28, 2011

This is an open-access article distributed under the terms of the Creative Commons Public Domain declaration which stipulates that, once placed in the public domain, this work may be freely reproduced, distributed, transmitted, modified, built upon, or otherwise used by anyone for any lawful purpose.

Funding: This work was supported by the National Institutes of Health, National Institute on Alcohol Abuse and Alcoholism (NIAAA) Division of Intramural and Biomedical Research. The funders had no role in study design, data collection and analysis, decision to publish, or preparation of the manuscript.

Competing Interests: The authors have declared that no competing interests exist.

*E-mail: midavis@mail.nih.gov

\section{Introduction}

Principle neurons in the telencephalon are organized into layers with distinct circuit and ensemble functions that can be surmised simply based on the location of the nuclei but the anatomical organization of the striatum has proven more challenging. This is because the striatum does not possess the readily identified laminar organization of most telencephalic structures and because the majority of striatal neurons are of one class, the GABAergic Medium Spiny Neuron (MSN) [1]. Recent studies have made use of the major distinction in MSN classes, differential expression of dopamine receptors (Drd1 or Drd2-GFP) in putative direct and indirect pathway neurons [2], respectively, to examine differential plasticity in the striatum but this technique only addresses one level of striatal complexity. The striatum is grossly divided into Dorsolateral (DLS), Dorsomedial (DMS) and ventral/Nucleus Accumbens (NAc). These divisions are roughly equivalent to motor, associative and limbic subdivisions but exist more as a dorsolateral to ventromedial gradient [3]. Regions can readily be identified for gross analysis but there is yet another layer of afferent-efferent and neurochemical heterogeneity within the striatum, the striosome-matrix organization.
Little is known about the differential function of the striosomes compared with the surrounding matrix. Existing data indicate that the dorsolateral matrix primarily serves motor functions [4] while partial ablation of dorsal striosomes impairs rotorod learning [5], suggesting cross talk between these regions during skill acquisition. Striosomes are a preferred striatal region for self-stimulation with implanted electrodes [6] and receive preferential and regionally selective innervation from the basolateral amygdala, prelimbic, infralimbic, orbitofrontal and anterior cingulate cortices and project primarily to the substantia nigra pars compacta (SNpc; reviewed in $[7,8,9])$. This is in contrast to dorsolateral matrix neurons, which receive innervation from sensorimotor cortex $[4,10,11]$. Matrix neurons are high in enkephalin, a marker of indirect pathway neurons, and project to the external segment of the globus pallidus (GPe) $[2,7]$. The matrix neurons are also the main target of vesicular glutamate transporter type two-containing thalamostriatal efferents [12]. Striosomal neurons contain substance $\mathrm{P}$ and dynorphin, markers of direct pathway neurons $[2,13,14,15,16]$. Direct pathway neurons should therefore concentrate in the striosomes while indirect pathway neurons should concentrate in the matrix. This simple division has not been supported with data using Drdl or Drd2-driven eGFP, however, 
and is further complicated by the observation that a $5-17 \%$ of striatal neurons co-express Drd1 and Drd2 depending on the region [2]. Combined, these data indicate that striatal organization and function is far more complex than either direct-indirect or striosome-matrix dichotomies imply.

Much of what is known about striosome-matrix organization and development has relied on catecholamine fluorescence $[17,18]$, receptor binding $[17,19,20,21]$ and immunohistochemistry $[22,23,24]$ but eGFP expression has recently been used to address differential development and plasticity in the two compartments. The proenkephalin-eGFP mouse has preferential matrix expression [25] and the early innervation by dopaminergic fibers using the Tyrosine Hydroxylase (TH)-eGFP mouse has been exploited to identify striosomes developmentally [26]. Fluorescent protein expression offers a static view based on differential transcriptional activity between neuronal populations but eGFP expression can also be used as a sensor of neuronal ensemble and immediate-early promoter activity [27]. Identification of a reporter line with differential expression in the striosome and matrix that is also a reporter of pathway/ensemble plasticity and activity would greatly expand our ability to address more sophisticated questions about striosome-matrix physiology in vivo and in situ.

The GENSAT database (www.gensat.org) was screened for images with differential striosome vs. matrix expression and we identified the Nr4al (Nuclear receptor subfamily 4, group A, member 1) line as a candidate activity-dependent reporter. The Nr4al gene (Entrez Gene ID: 15370, http://www.ncbi.nlm.nih. gov/gene/15370) is also known as GFRP1, Gfrp, Hbr-1, Hbrl, Hmr, N10, NGFI-B, NGFIB, NP10, TIS1, TR3 and Nur77. Nr4al is a widely expressed orphan of the steroid-thyroid hormone receptor superfamily that is readily inducible at the level of transcription. Nuclear Nr4al monomers bind the NGFI-B response element while homodimers bind the Nur77 response element and $\mathrm{Nr} 4 \mathrm{a}$ l heterodimerizes with the retinoic acid receptor to bind the DR5 motif (reviewed by [28]). The Nr4al promoter contains consensus sites for multiple transcription regulators and is induced by calcium, protein kinase $\mathrm{C}$, mitogen-activated protein kinases and cAMP dependent transactivation depending upon the cell type [29,30,31,32,33] while Nr4al protein is subject to extensive post-transcriptional regulation $[34,35,36]$. Nr4al induction parallels other immediate early genes within the basal ganglia. Nr4al mRNA [37], but not protein [38], is enriched in direct pathway neurons. Nr4al is induced by psychostimulant exposure $[39,40,41]$ and during opiate withdrawal $[42,43]$. Antipsychotics also induce Nr4al expression throughout the basal ganglia, although the pattern and level of induction vary with drug subclass and even among members of the same pharmacological class [44]. Together, these data implicate the Nr4al gene in plasticity in the basal ganglia that occurs during psychostimulant and antipsychotic exposure and suggest that the pattern of induction may be reflective of differential pharmacological effects within the circuit.

A reporter mouse strain with inducible expression would therefore be useful for identifying circuits involved in short and long term plasticity after stimulant and antipsychotic exposure but also with striatal-based learning paradigms. Here we report the characterization of striosome-matrix and activity-dependent expression of eGFP from the Nr4Al promoter as both an anatomical marker for striosomes and a reporter for activity in the extended striatum. Expression occurs primarily in Drdl+ neurons but the level of basal and stimulated expression varies with compartment, thereby differentiating Drdl striosome neurons from Drdl matrix neurons. These mice will be useful for examination of drug- or activity-dependent Nr4al induction in the extended striatum associated with learning and plasticity as well as for in situ identification of neurons differentially activated within the striosome and matrix compartments.

\section{Results}

\section{Distribution of Nr4a1-eGFP in the Mature Basal Ganglia}

Nr4al promoter driven eGFP expression was observed in distinct cell populations throughout the brain and periphery (Figs. Sl and $\mathrm{S} 2$ ). eGFP levels were particularly high in the mature striatum but the pattern was distinct from both Drd1-eGFP and Drd2-eGFP expression (Fig. 1). Expression in the dorsal striatum was striosomelike in the Nr4al strain (Fig. 1 Al) but uniform in both the Drdl (Fig. 1 B1) and Drd2 (Fig. 1 C1) strains. The expression pattern is in agreement with previous reports using the Drdl and Drd2 strains [2]. Nr4al-eGFP was laminar in the ventromedial striatum and patch/swirl-like in the shell of the NAc (Fig. 1 A2). A similar heterogeneous expression pattern was apparent in the Drdl-eGFP strain (Fig. 1 B2) although these regions of intense expression in the NAc shell covered a larger area in the Drdl-eGFP strain. Drd2eGFP expression was more uniform in the ventral striatum and NAc (Fig. 1 C2) but, unlike the Nr4al and Drdl strains, was low in the NAc shell. Expression within fibers in the GP was low in both the Nr4al (Fig. 1 A3) and Drdl (Fig. 1 B3) strains but robust in the Drd2 strain (Fig. 1 C3). Expression was also detected in fibers in the SN of both the Nr4al (Fig. 1 A4) and Drdl (Fig. 1 B4) strains. Regions of patchy innervation were sometimes observed in the SNpc of the Nr4al strain (Fig. 1 A4). In contrast, expression in the ventral mesencephalon of the Drd2 strain was mainly restricted to somata within the SN and Ventral Tegmental Area (VTA; Fig. 1 C4). This pattern of expression is consistent with $\mathrm{Nr} 4 \mathrm{al}$ expression being primarily in direct pathway neurons but is not identical to Drdl-eGFP expression. Direct pathway neurons project primarily to the SN, however, collaterals also innervate the GP $[45,46]$, therefore expression in this region may be eGFP in these collaterals, fibers en passant or could represent a subpopulation of indirect pathway neurons that express Nr4al-eGFP [39]. The differential intensity of the innervation of the $\mathrm{SNpc}$ may represent the terminals of striosome neurons, which are known to project preferentially to the $\mathrm{SNpc}$ and have segmented striosome-matrix projections [7,9].

Serial sections through the striatum and amygdala (Fig. 2) revealed striosomes that form near-contiguous layers. The subcallosal streak and lateral striatal streak have contiguous expression, framing the striatum (Fig. 2 rows 1, 2). These cells were similar in intensity and proximity to fiber tracts as cells of the lateral and medial Intercalated Cells (ITC) of the amygdala (Fig. 2 row 6). Apparent layers in the striatum are often interrupted by blood vessels and fiber bundles, particularly in dorsomedial regions, but resemble the laminar organization previously demonstrated in a serial reconstruction [47]. Rows in the matrix have been identified in anterograde tracer studies from motor cortex [11] but these lamina also resemble striosomes innervation from deep layer prefrontal cortex developmentally and in the adult [48], indicating that the projections to the striosome and matrix may be arranged in parallel. Striosomes were also frequently observed in close proximity to and surrounding large blood vessels, as has previously been noted [49]. Layers were curved parallel to the corpus callosum in the dorsal and lateral regions of the rostral striatum but formed dorsomedial to ventrolateral layers in the ventral striatum (Fig. 2 rows 2, 3). Nr4al-eGFP expression in the NAc, Bed Nucleus of the Stria Terminalis (BNST) and amygdala was high and variable between animals but was never uniform (Fig. 2 rows $4-6$ ). High expression was evident in the striatal 


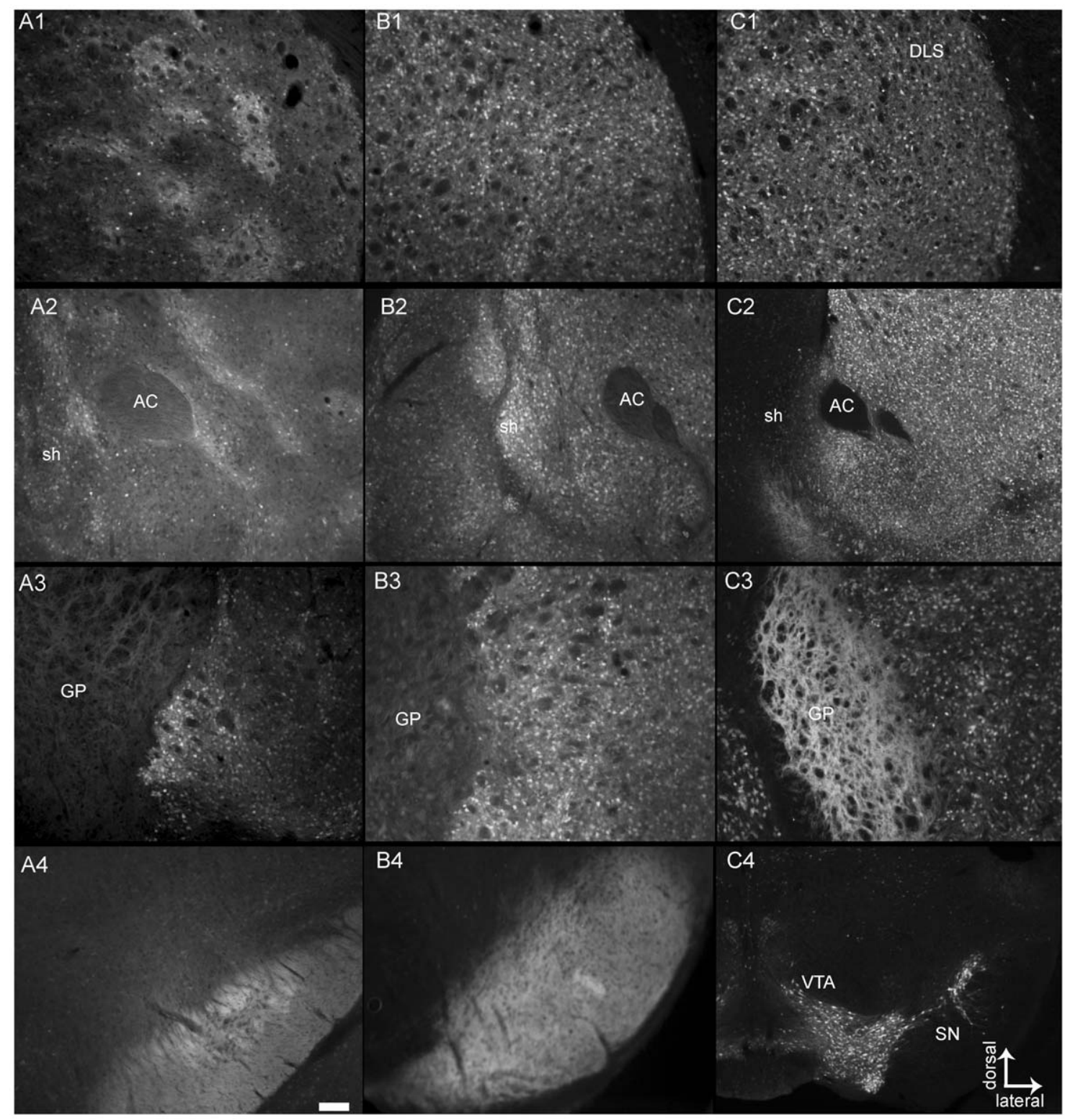

Figure 1. Nr4a1-eGFP expression in the basal ganglia. Nr4a1-eGFP expression (A1-A4) in the striatum and striatal projection areas compared to Drd1-eGFP (B1-B4) and Drd2-eGFP (C1-C4) expression in the mature mouse. The DLS is shown in row 1, ventral striatum in row 2, globus pallidus in row 3 and SN/VTA in row 4 . The scale bar, $200 \mu \mathrm{m}$, applies to all images.

doi:10.1371/journal.pone.0016619.g001

fundus (Interstitial Nucleus of the Posterior limb of the Anterior Commissure, IPAG, Fig. 2 row 5) that continued into the ITG of the amygdala and the Central nucleus of the Amygdala (CeA). The CeA contained numerous intensely fluorescent MSN-like cells. eGFP expression within the lateral amygdala and basolateral amygdala was sparse with low level expression in large neurons.

Multi-label immunofluorescence was used to verify striosomal expression of eGFP in the Nr4al strain (Fig. 3). Calbindin 28K is a marker for matrix neurons in the mature striatum $[50,51,52]$ and reciprocal expression occured between Nr4al-eGFP and the matrix-associated calcium-binding protein calbindin $28 \mathrm{~K}$ in the striatum (Fig. 3, A1-B3). This was apparent in both rostral (Fig. 3, A1-A3) and caudal regions (Fig. 3, B1-B3). Fluorescence was also apparent in the surrounding matrix cells in the adult mouse brain but at a lower intensity. Calretinin immunoreactive fibers from the paraventricular nucleus of the thalamus were present in striosomes (Fig. 3, C1-C3) in the limbic and associative striatum in a gradient that increased from the dorsolateral to ventromedial direction and along the septal pole $[53,54]$. eGFP overlapped with this marker in more dorsomedial regions but eGFP was stronger in the weakly calretinin innervated subcallosal streak while calretinin-immunoreactive fibers were more dense in the medial and ventral striatum (see below). The classical striosomal marker, the mu-OR, also colocalized with Nr4al-eGFP in the dorsal striatum (Fig 3, D1D3).

Heterogeneous eGFP expression was also observed in the extended striatum, including the NAc, BNST, ITC and the CeA. Images through the extended striatum (Fig. 4) reveal overlap with the mu-OR in the ventral striatum and NAc in laminar and swirled patterns (Fig. 4, A1-A3). "Columns" and "zones" have been used to described these regions based on differential 


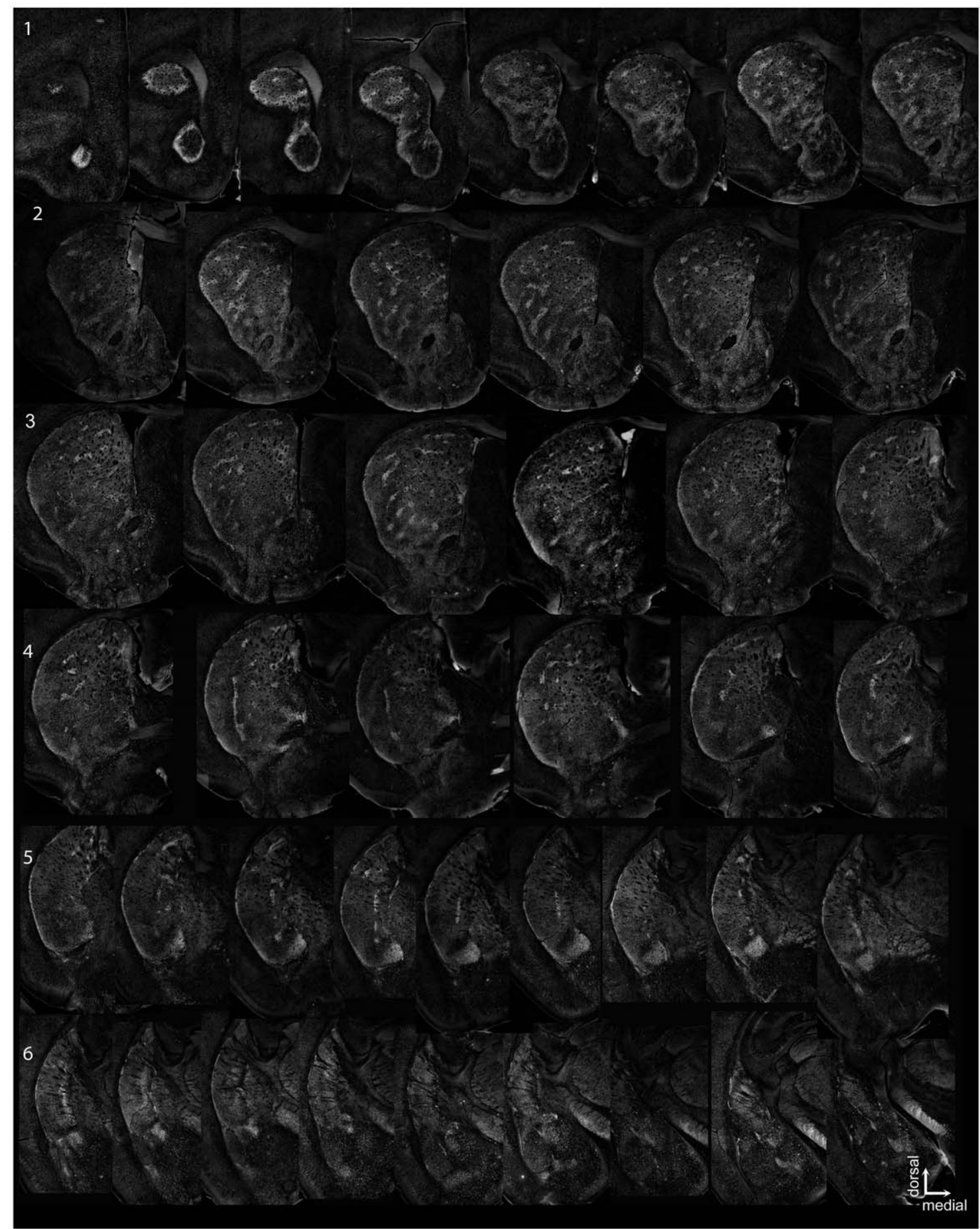

Figure 2. Serial sections through the striatum and extended amygdala of a mature Nr4a1-eGFP mouse. Striosomes appear brighter than the surrounding matrix, particularly the subcallosal streak (rows 1-2) and lateral striatal streak (rows 3-5), while a laminar organization is apparent in the ventromedial striatum (rows 1-4). Regions of intense expression are also present within the BNST (rows 4 and 5), the striatal fundus (IPAC, row 5) and within the intercalated cells of the amygdala (row 6). A uniform background level was subtracted from these images using Image J. When sections were missing or damaged, adjacent or contralateral sections were substituted. Intervals - range from 80-120 $\mu \mathrm{m}$. Due to differences in mouse strain of the reference atlas (Allen Brain Atlas, C57/B/6J) and tissue shrinkage the coordinates are approximate. doi:10.1371/journal.pone.0016619.g002

neuropeptide and calcium binding protein expression $[53,55,56,57]$. Anterograde tracing of deep layer prefrontal afferents identified a similar laminar distribution in the ventral striatum and NAc [48]. Most subregions of the BNST (Fig. 4, B1-
B3) contain mu-OR and Nr4al colocalization; however, interestingly, the IPAC at the lateral edge and ventral to the posterior commissure does not contain high levels of mu-OR but expresses Nr4al-eGFP (arrow, Fig. 4 B3). 

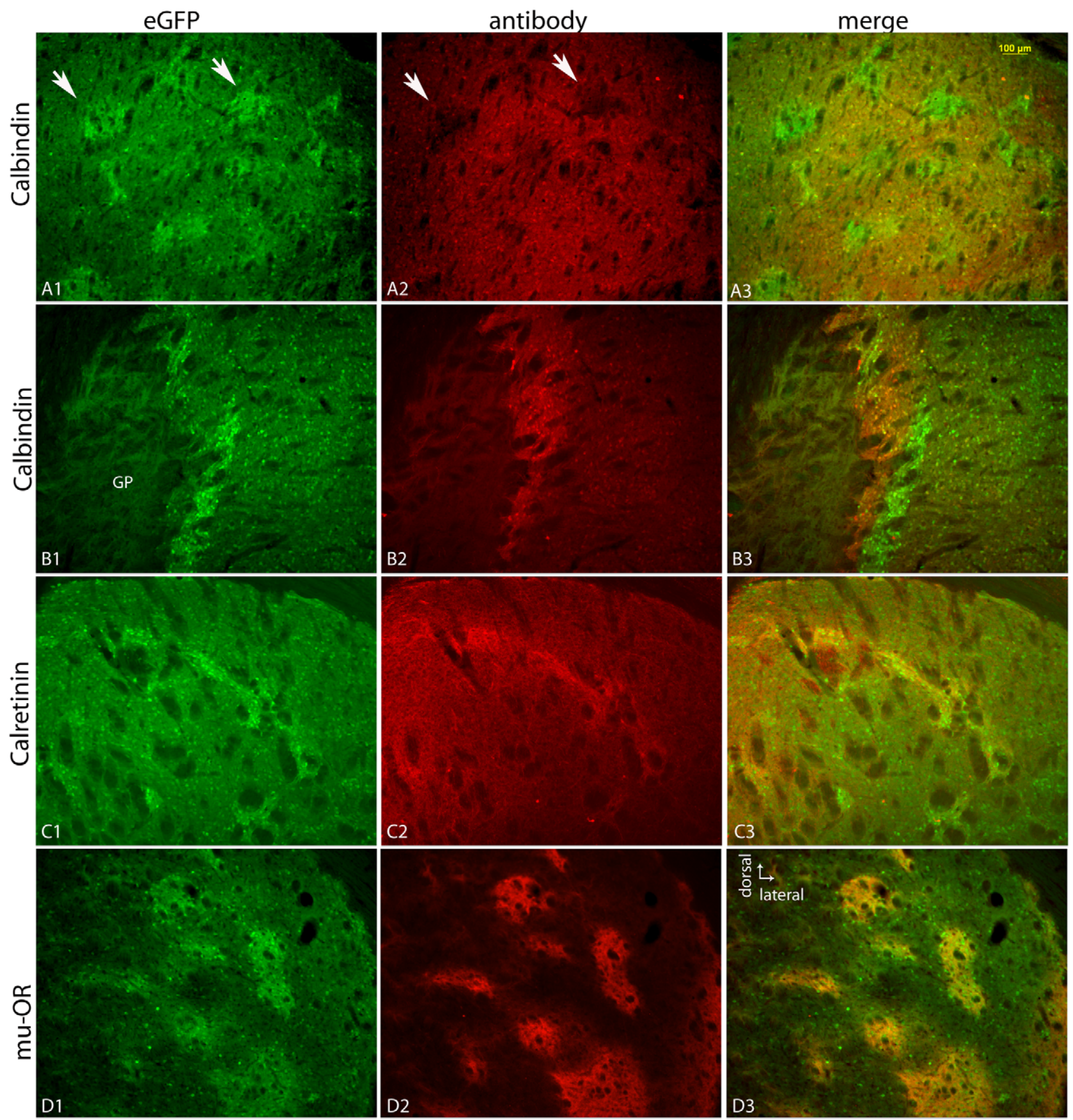

B 2
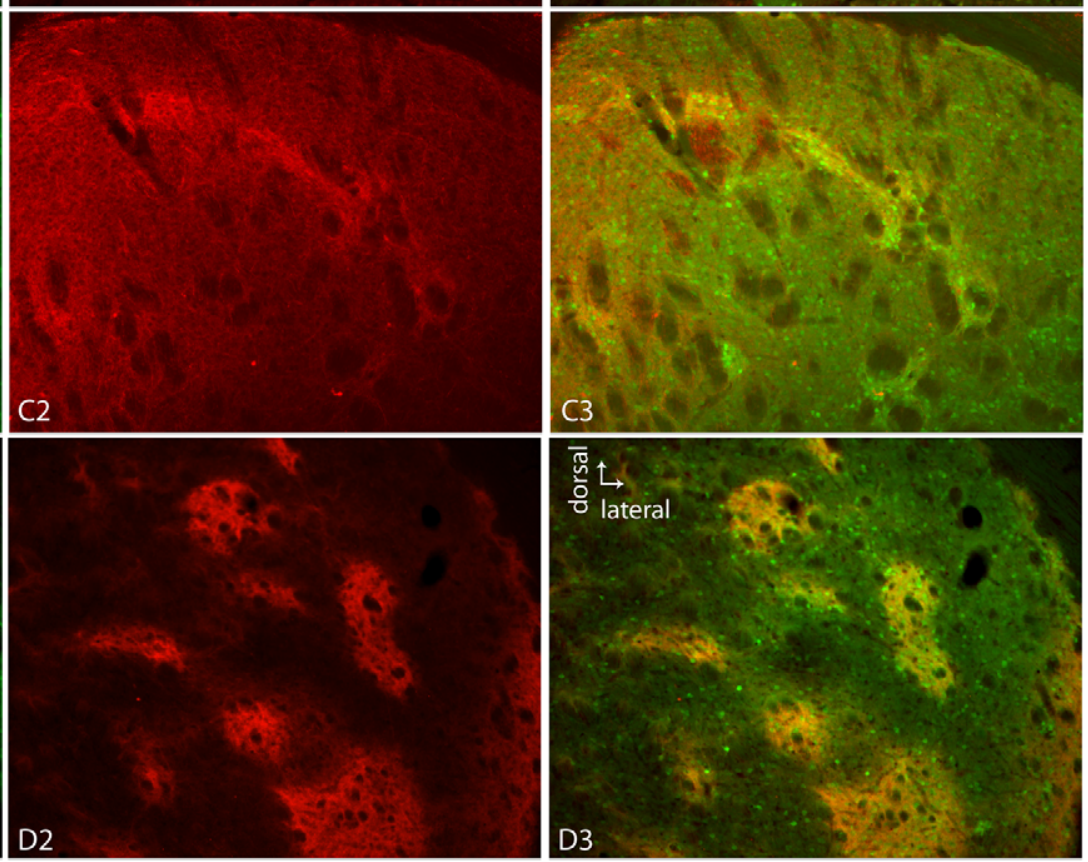

Figure 3. Nr4a1-eGFP expression in the striatum compared to the matrix marker calbindin $28 \mathrm{~K}$ and striosome markers calretinin and mu-OR. eGFP is shown in the left column. Calbindin expression in the dorsolateral striatum (A2) and globus pallidus/caudal striatum (B2) is merged with eGFP in A3 and B3. Calretinin immunoreactivity in the dorsomedial striatum is shown in C2 and merged with eGFP in C3. Mu-OR activity (D2) is merged with eGFP in D3. The scale bar in A1 $(100 \mu \mathrm{m})$ applies to all panels. doi:10.1371/journal.pone.0016619.g003

It has been previously suggested the ITC neurons are striatal in origin [58] and recent studies have confirmed this by mapping lineage-specific transcription factors [59,60]. Like striosomes, the ITC is rich in mu-OR expression [61] and mu-OR immunoreactivity overlaps with Nr4al-GFP expression in the ITC (Fig. 4, G1-C3). The ITC is also rich in dopaminergic fibers [62] and TH immunoreactivity overlaps with Nr4al expression in the ITC (Fig. 4, D1-D3). This overlap is not as robust in the CeA where $\mathrm{Nr} 4 \mathrm{al}$ expression is lighter overall but areas of high Nr4al-GFP expression are observed, particularly in the medial region that receives dense dopaminergic innervation (Fig. 4, D1-D3). For comparison, Drd1-eGFP expression in the CeA and ITC revealed both low Drdl immunoreactivity and low eGFP levels in the CeA but high expression in the ITC (Fig. 4, E1-E3). While Nr4al expression is consistent with the ITC being striosome-like, Drdl immunoreactivity and Drdl-eGFP expression suggests the CeA has fewer Drdl and mu-OR expressing neurons and lower Nr4al expression under basal conditions than the ITC. Combined, this 

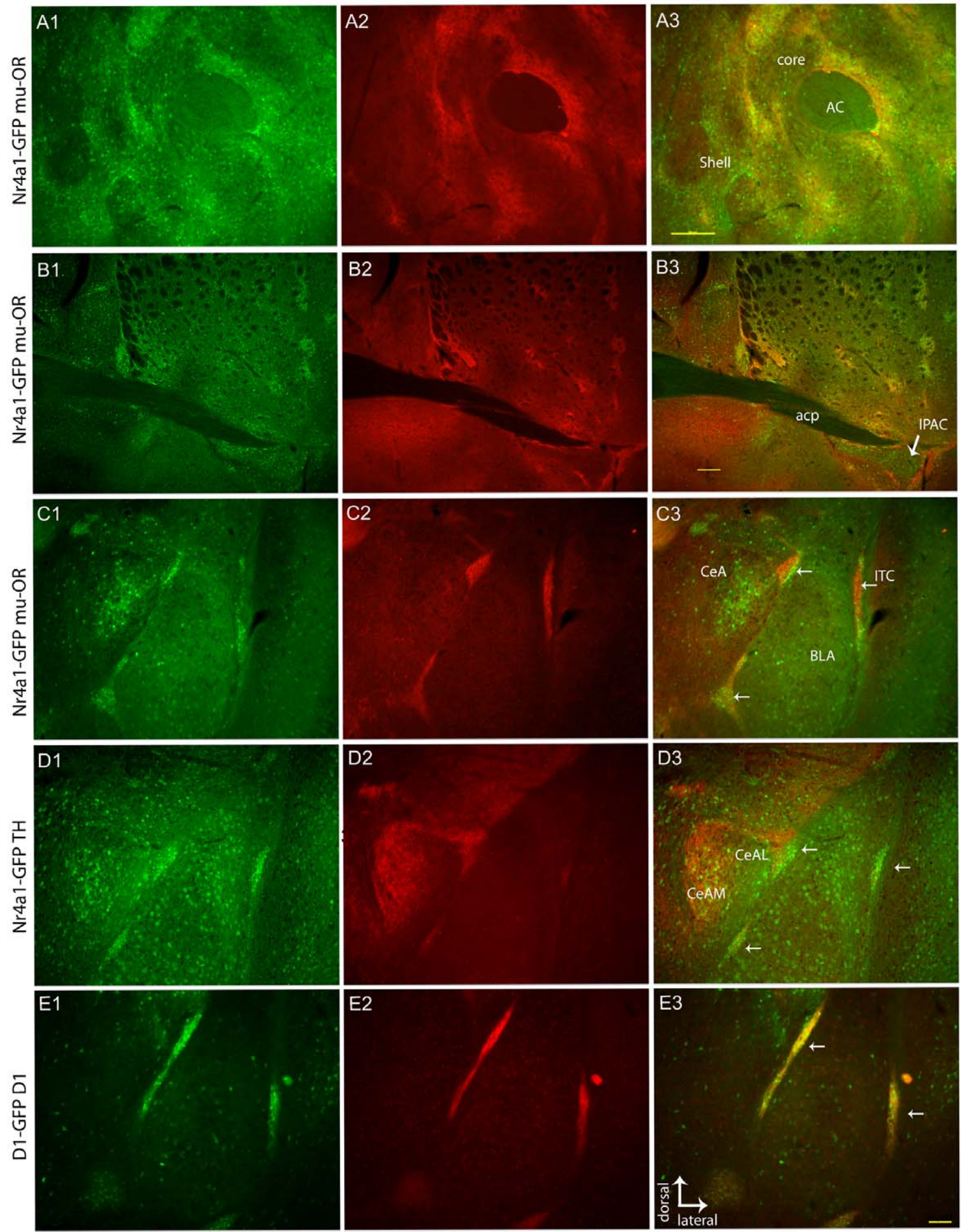

Figure 4. Nr4a1-eGFP expression compared with striosomal markers in the extended striatum and amygdala. Nr4a1-driven eGFP expression is present in the NAC (A1), BNST (B1) and amygdala (C1, D1). Robust colocalization with mu-OR is observed in the NAc core but not the shell (A2, A3). The BNST shows heterogeneous eGFP expression (B1) that overlaps with mu-OR immunoreactivity in most subregions (B2, B3). Mu-OR immunoreactivity in the amygdala (C2) overlaps with Nr4a1-eGFP expression in the ITC (C3, arrows) but not in the CeA. TH immunoreactivity is not uniform with greater innervation of the medial $\mathrm{CeA}(\mathrm{CeAM})$ than lateral $\mathrm{CeA}(\mathrm{CeAL})$ at this level (D2). TH+ fibers innervating the ITC were faint compared to the medial CeA but overlapped with the ITC (D2, D3). Drd1-eGFP expression (E1, E3 merge) and Drd1 immunoreactivity (E2, E3) in the amygdala are shown for comparison. Scale bars in A3 and B3 are $200 \mu \mathrm{m}$. Scale bar in E3 is $100 \mu \mathrm{m}$ and applies to panels C-E. doi:10.1371/journal.pone.0016619.g004 
pattern of immunoreactivity is consistent with the ITC being derived from the lateral ganglionic eminence and phenotypically striosome-like [59].

$\mathrm{Nr} 4 \mathrm{al}$ is extensively regulated at the post-transcriptional level and the protein has a short half-life of $2-4$ hrs $[36,63]$, therefore eGFP levels (half-life $\sim 26 \mathrm{hrs}$ ) may not reflect native protein levels (supplemental text in [64]). Immunostaining for Nr4al in neonatal mice indicated extensive overlap in expression of eGFP and endogenous protein levels in the dorsal striatum (Fig. 5 A1-3, B13). However, expression diverged in the adult striatum with very little correlation between the endogenous nuclear protein levels and eGFP, particularly in the matrix where Nr4al immunoreactivity was detected in eGFP negative cells. Nr4al expression was primarily localized to the nucleus in the developing and mature animals (Fig. 5 A2, C2) but a background haze was also present, consistent with descriptions of $\mathrm{Nr} 4 \mathrm{al}$ mitochondrial localization $[34,35]$.

\section{Development of Nr4a1-eGFP Expressing Striosomes}

Dopaminergic innervation of the developing striatum has been extensively studied. Striosome neurons are born first and occupy "dopamine islands" that are rich in dopamine and TH
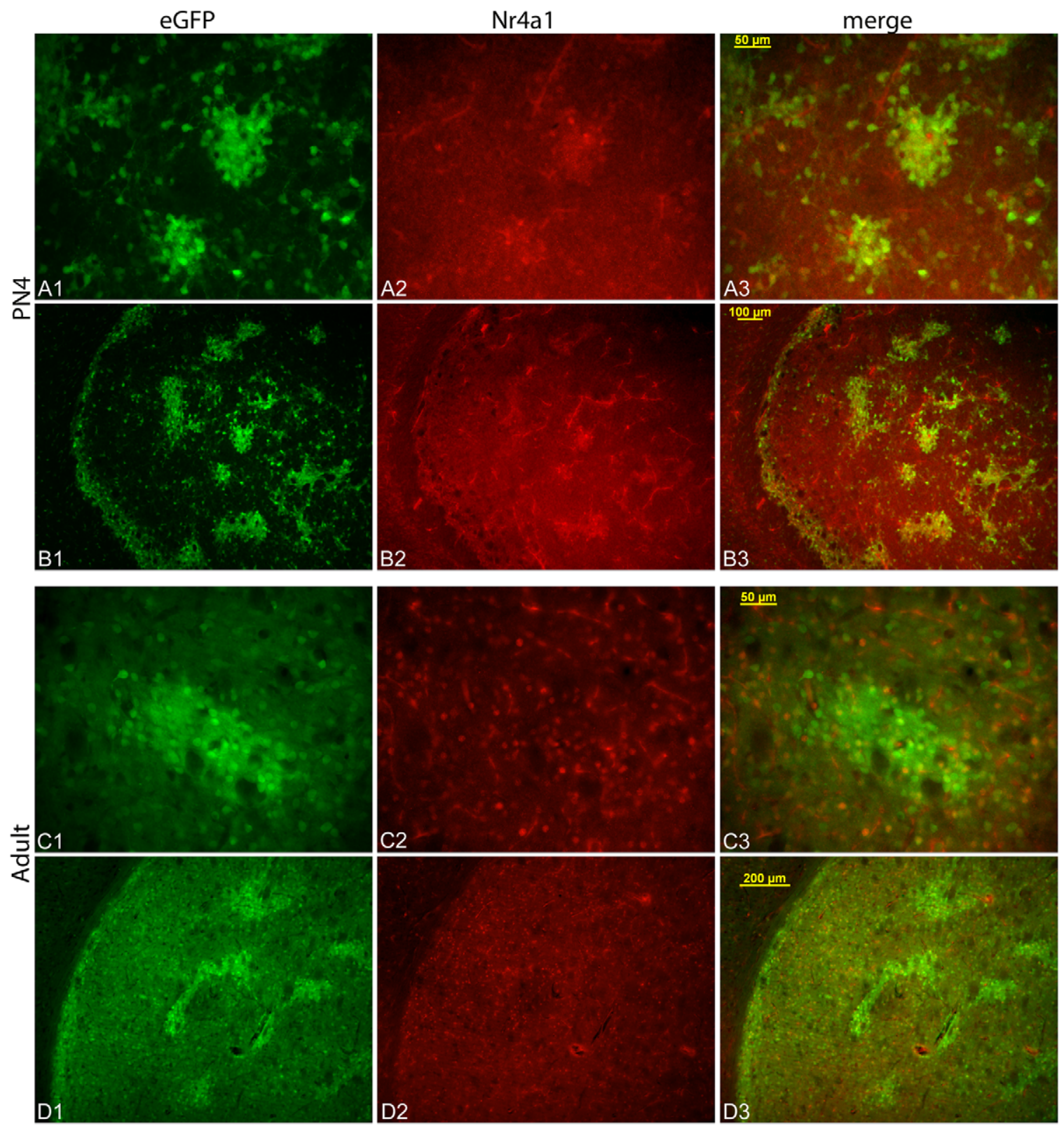

Figure 5. Immunolocalization of endogenous $\mathrm{Nr4a} 1$ in the developing and adult striatum. Dorsolateral striatum from a neonatal (PN3/4, $\mathrm{A}, \mathrm{B}$ ) and mature mouse (PN30, C, D). Higher power images indicate colocalization of eGFP and nuclear Nr4a1 in the developing dopamine islands (A1-A3) that is present throughout the structure at low power (B1-B3). In contrast, there is little overlap between nuclear Nr4a1 expression and eGFP in the mature striatum (C, D). High power images detected a speckled distribution (C2) in addition to nuclear localization. The lack of correlation between eGFP levels and Nr4a1 is shown in low power images of the mature dorsolateral striatum (D1-D3). The scale bars in A and C are $50 \mu \mathrm{m}$, $100 \mu \mathrm{m}$ for B and $200 \mu \mathrm{m}$ for D.

doi:10.1371/journal.pone.0016619.g005 
immunoreactive fibers $[18,65,66]$ and the Drdl dopamine receptor $[67,68]$. This pattern of expression extends into the neonatal period $[67,68,69,70]$. When eGFP was examined in horizontal sections from the newborn (Post Natal, PN 3/4) Nr4aleGFP striatum, an island-like expression pattern was observed with very little expression in the developing matrix compartment (Fig. $6 \mathrm{~A} 1, \mathrm{~B} 1, \mathrm{C} 1$ ). This pattern of expression overlapped with Drdl immunoreactivity (Fig. 6 A2, A3) and was not due to differences in cell density observed with DAPI binding (Fig. 6 A4, A5). A similar pattern of colocalization was observed with $\mathrm{TH}$ immunoreactivity (Fig 6 B1-B3) and DAPI staining is shown for comparison (Fig. 6 B4). Mu-OR staining showed robust overlap in the medial striatum at this age (Fig. 6 C1-C3) but eGFP was stronger in the ventrolateral and caudal regions where mu-OR immunoreactivity was absent (Fig. 6 C3).

TH immunoreactivity in horizontal sections through the neonatal striatum indicated selective dopaminergic innervation of the developing striosomes and a close association between the developing dopamine system and eGFP expression. Developing striosomes are also rich in $\operatorname{TrkB}[71]$ and cortical afferents are the main source of BDNF [72]. Thus, cortical afferents may play a role in striatal maturation. Nr4al expression overlaps with TrkB in both dorsal (Fig. 7, A1-A3) and ventral (Fig. 7, B1-B3) striosomes. This was consistent throughout the striatum but not in the subcallosal streak and the lateral striatal streak at PN3/4 (Fig. 7, B1-B3) where Nr4al-eGFP was expressed at high levels but TrkB immunoreactivity was low. Concordance with these established developmental patterns suggested that Nr4al-eGFP is closely associated with Drdl expression and dopaminergic activity in the developing striatum but association with TrkB suggests a role for cortical afferents in Nr4al-eGFP expression during striosome development. Low expression of TrkB and mu-OR in the ventral/ lateral striatal streak suggests that these striosome-like regions may be physiologically or developmentally divergent.

Nr4al induction can be mediated by numerous overlapping signaling pathways but CREB is a common stimulus for activation in multiple systems [28]. We therefore surmised that CREB and/ or ERK may be involved due to the overlap with Drdl and TrkB expression in the developing neonatal striatum. Surprisingly, immunofluorescent detection of Ser 133 phosphorylated CREB (p-GREB) revealed a reciprocal expression pattern relative to Nr4al-eGFP at PN3/4 (Fig. 8, A1-A3). pCREB was also observed in the adjacent vasculature at PN3/4. By PN7, pCREB immunoreactivity increased in both compartments and overlap could be observed in cells at the edges of the striosomes and in scattered matrix cells (Fig. 8, B1-B3). In contrast, ERK activation overlaps with Nr4al-driven eGFP expression at both PN3/4 (Fig. 8, C1-C3) and PN7 (Fig. 8, D1-D3), although the dominant pattern of immunoreactivity shifted with time. At PN3/4, pERK was present primarily within striosomal nuclei (Fig. 8, C1) but this shifted to a combined diffuse and nuclear pattern by PN7 (Fig. 8, D1). pCREB is probably not the main transactivating mediator of Nr4al-eGFP expression in developing striosomal neurons but ERK-mediated pathways are differentially active in striosomes.

\section{Inducible Expression of Nr4a1-eGFP}

Sensitization to psychostimulants has been suggested to occur through striosomal activation $[8,73]$ and a single exposure to amphetamine is sufficient to induce immediate-early genes in striosomes [74,75]. A high dose of methylphenidate $(5 \mathrm{mg} / \mathrm{kg})$ was administered to mice by i.p. injection at PN 30 to determine whether eGFP could be induced in a similar fashion to these endogenous immediate-early genes in vivo. Sections from littermate heterozygous mice are presented side by side at 4 levels through the striatum (Fig. 9). MPH increased eGFP levels in the striosomes and the striatal matrix compartment of the DLS (right column) that is consistent with increased locomotor activity. Striatal induction is similar to endogenous Nr4al induction [39] as well as Zif/268, Fos and Arc after psychostimulant exposure $[74,75,76]$.

The apparent activity-dependent regulation and the pattern of expression developmentally suggests a strong association between glutamatergic afferents, dopaminergic afferents, TrkB, ERK and Nr4al-eGFP expression. However, the lack of colocalization of pCREB and eGFP implicates another level of Nr4al regulation in the developing striatum. To determine potential factors regulating the Nr4al promoter, MSNs were cultured and treated in vitro with BDNF, forskolin, the Drdl agonist SKF-83822 or $30 \mathrm{mM}$ $\mathrm{KCl}$ for 3-20 hrs. Fluorescence was measured in a microplate fluorometer and examined microscopically (Fig. 10). Cultures contained contaminating glia and large, pyramidal-like cells but MSNs were readily identifiable by morphology and the presence of spines. Stimuli produced different patterns of native fluorescence in the cultures. Expression was infrequent under control conditions (Fig. 10A) with scattered clusters of brightly fluorescent cells visible. BDNF increased fluorescence, filling the cell bodies and making processes of MSNs and contaminating large pyramidal-like cells visible when imaged at the same exposure time as control cells (Fig. 10B). Forskolin increased fluorescence in neuronal-like cells but also induced low level eGFP in contaminating glial cells. Significant differences in eGFP levels were not observed in SKF-83822-treated cells at $20 \mathrm{hrs}$ (Fig. 10D). High extracellular potassium increased eGFP in neurons, with eGFP filling the processes (Fig. 10E). A time course for eGFP expression in response to stimulation measured in lysates is presented in Fig. 10F. Only forskolin stimulation was sufficient to increase eGFP levels after $3 \mathrm{hrs}$, reaching a maximum increase of $72 \%$. eGFP levels were increased by $8 \mathrm{hrs}$ with forskolin, SKF-83822 and $\mathrm{KCl}$ stimulation but $20 \mathrm{hrs}$ was required to detect a $16 \%$ increase with BDNF-stimulated eGFP induction. Levels increased or reached a plateau over time with forskolin and $\mathrm{KCl}$ treatment $(40 \%)$ while SKF-83822 induction (32\%) was transient.

Induction and translation of eGFP sufficient to be detected fluorometrically in vitro required $3-20 \mathrm{hrs}$ depending on the stimulus, however the half life of Nr4al is $2-4 \mathrm{hrs}[31,36,63]$. The discrepancy between eGFP expression and native Nr4al expression in the mature brain was also noted above with immunofluorescence (Fig. 5). To address these differences we performed time course experiments for $\mathrm{Nr} 4 \mathrm{al}$ and eGFP mRNA and protein expression (Fig. 11). Cultures were stimulated with $30 \mathrm{mM} \mathrm{KCl}$ for 0.5 to $8 \mathrm{hrs}$ and semi-quantitative RT-PGR used to detect mRNA (Fig. 11A). Nr4al mRNA peaked at 1 hour while eGFP mRNA remained elevated through the 8 hour time point. eGFP protein levels detected by Western blot paralleled eGFP mRNA (Fig. 11B) but there was no correlation between Nr4al protein levels and Nr4al mRNA in lysates. This could result from differential responses in different MSN subtypes or other posttranscriptional factors; therefore, we examined the expression of Nr4al by immunofluorescence. MSN cultures are heterogeneous with respect to direct vs. indirect phenotype but also in the basal level of Nr4al-eGFP expression with clusters of brightly fluorescent cells (Fig. 11 C). Nr4al was detected at 2 hrs in the nuclei of the brighter cell population (red channel, Fig. 11 G1, C2) but was absent from the nuclei of these cells at $8 \mathrm{hrs}($ Fig. $11 \mathrm{C} 3$, $\mathrm{C} 4$, nuclei indicated by the arrows in C4). Interestingly, at $8 \mathrm{hrs}$ both Nr4al and eGFP immunoreactivity could be observed in a perinuclear pool in cells with little other cellular eGFP expression (Fig. 11 C3, arrows). This pattern is consistent with ER 


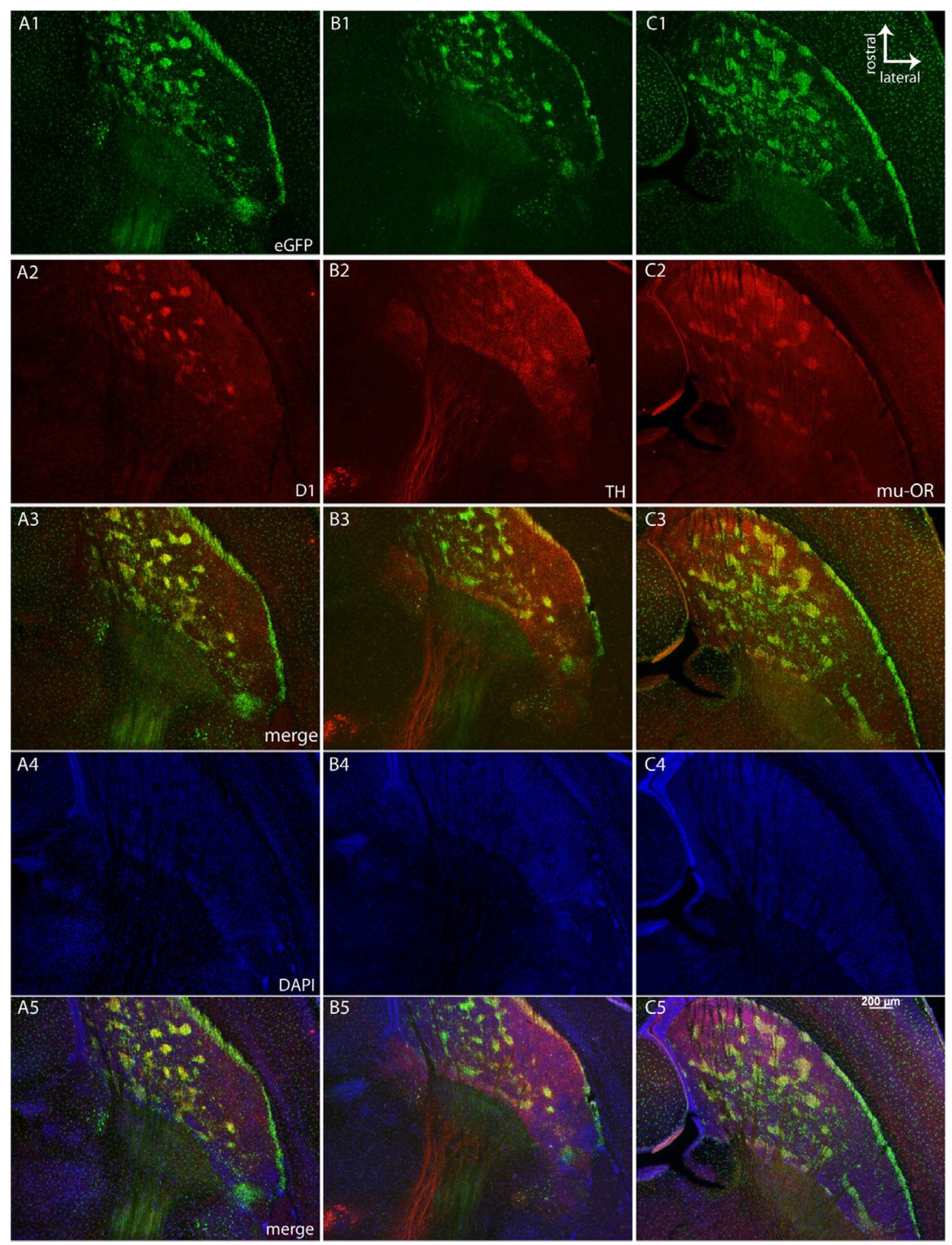

Figure 6. Developmental expression of Nr4a1 in striatonigral projections compared to Drd1, TH and mu-OR in horizontal sections. eGFP expression (A1, B1, C1) overlaps with Drd1 immunoreactivity (A2, A3, A5 merged with the DAPI channel) and TH immunoreactivity (B2, B3, B5 merged with the DAPI channel) Mu-OR immunoreactivity (C2) colocalized with Nr4a1-eGFP is shown in C3 and in C5 merged with the DAPI channel. DAPI staining is less intense in the striosomes (A4, B4, C4), indicating that the striosome-like distribution is not due to increased cell density. The scale bar in $\mathrm{H}(200 \mu \mathrm{m})$ applies to all images. Panels A and B were taken with a Zeiss Axiovert microscope. Panels in C were taken with a Zeiss Lumar stereomicroscope.

doi:10.1371/journal.pone.0016619.g006 

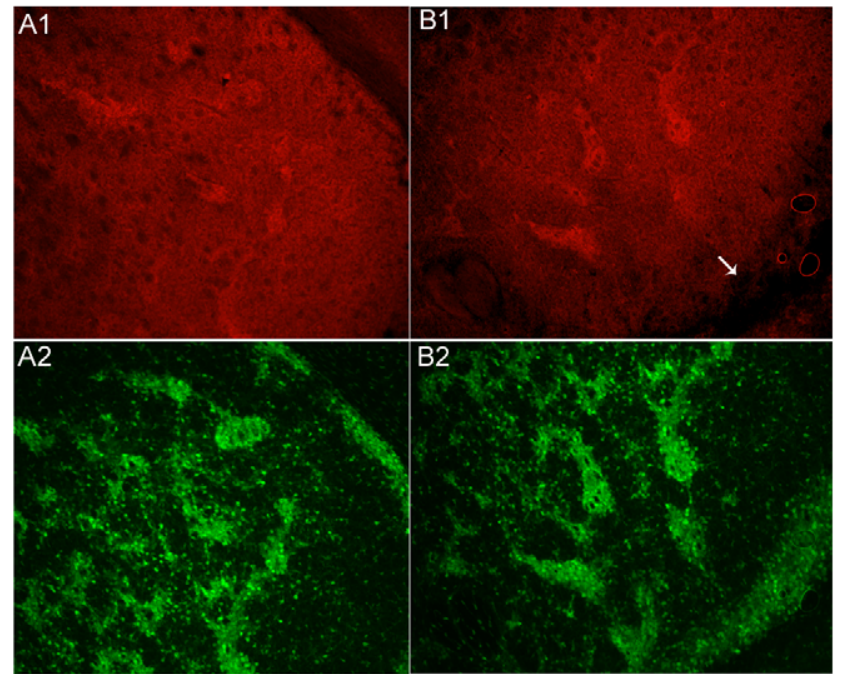

A3
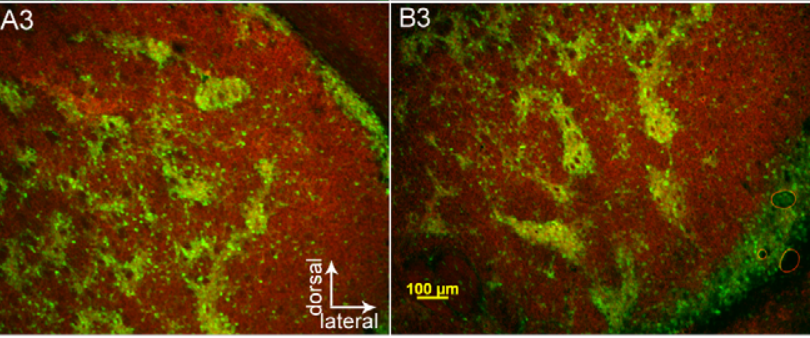

Figure 7. TrkB and Nr4a1 are co-expressed in developing striosomes. TrkB expression (A1, B1) and Nr4a1-eGFP (A2, B2) merged $(A 3, B 3)$ in the developing striosomes at PN3/4. Dorsolateral $(A)$ and ventrolateral striatum (B) are shown. Arrow (B1) indicates the lateral striatal streak. Scale bar in J $(100 \mu \mathrm{m})$ applies to all images. doi:10.1371/journal.pone.0016619.g007

localization and suggests a different rate of transactivation or translation in this population of cells. It should also be noted that as with immunostaining in the mature brain (Fig. 5), cultures had diffuse staining consistent with mitochondrial localization of $\mathrm{Nr} 4 \mathrm{al}$ $[34,36]$.

To further characterize the MSN subtypes with high eGFP expression, cultures treated with $30 \mathrm{mM} \mathrm{KCl}$ were stained for Drdl and met-enkephalin immunoreactivity to determine the cell type with robust activation of the Nr4al promoter (Fig. 12). We tested multiple sources of other markers but unfortunately only the Drdl and met-enkephalin antibodies proved reliable. Intense expression of eGFP (Fig. 12A) was frequently seen in clusters of Drdl+ cells (Fig. 12B). Approximately half of the Drd1+ cells did not express high levels of eGFP (merged image, Fig. 12C). Cells expressing eGFP but no Drdl were infrequent $(\sim 5 \%)$ and often small and bipolar in morphology (arrow, Fig. 12A). eGFP (Fig. 12D) colocalized with punctate/vesicular met-enkephalin immunoreactivity in $\sim 15 \%$ of neurons (Fig. 12E, merge in F).

\section{Discussion}

Expression of eGFP from the Nr4al promoter is observed throughout the body and nervous system (Figs. S1 and S2). Expression is not ubiquitous in the brain but within distinct neuronal populations in each brain region, particularly in the striatum, NAc and striatal-like regions of the amygdaloid complex. We characterized expression in the mature animal and explored the utility of this strain for experiments examining striosomematrix interactions, ontogeny and differential plasticity. Double label immunofluorescence with classical striosome and matrix markers confirmed higher expression in the adult striosomes and concordant expression in developing striosomes. Expression in vivo was temporally and spatially associated with the developing corticostriatal and dopaminergic pathways. Nr4al-eGFP expression overlaps spatially with dopaminergic innervation, Drdl expression, TrkB expression and ERK phosphorylation in the neonatal striatum. In vivo exposure to methylphenidate (Fig. 9) and in vitro stimulation increases eGFP expression (Figs. 10, 11, 12) indicating activity-dependent regulation. Thus the Nr4al strain is not only an architectural marker of striosomal neurons but also as an inducible reporter of MSN activity.

The Nr4al mouse has distinct expression in striosomal neurons under basal conditions and $\mathrm{Nr} 4 \mathrm{al}$ is enriched in direct pathway neurons (Figs. 1, 6 and 12). Lobo and colleagues [37] identified Nr4al as a differentially expressed (1.5 fold) mRNA species in array studies of FACS sorted Drd1- and Drd2-eGFP neurons. These data agree with the difference in eGFP levels between direct and indirect pathway neurons but low eGFP expression in indirect pathway neurons in the Nr4al-eGFP mouse suggest more heterogeneity than simply direct and indirect. This is further complicated by the observation that $\mathrm{Nr} 41$ is expressed in Drd2/ enkephalin expressing neurons (Fig. 12 and [33,37,39]). Backman and Morales [39] estimated that 25\% of met-enkephalin+ neurons expressed $\mathrm{Nr} 4 \mathrm{al}$ after amphetamine exposure, which is slightly higher than the $15 \%$ co-expression we observed. The neurons in the matrix in Fig. 5 that do not express eGFP but have endogenous Nr4al immunoreactivity and the matrix cells expressing eGFP after MPH exposure may be these Nr4alexpressing indirect pathway neurons but these disparities also point to a complex mode of regulation that differs between the striosome and matrix, as has been suggested to exist for phosphorylation of CREB [77].

Differential (high and low) eGFP expression in the striosome and matrix of primarily Drdl-expressing cells under basal conditions and in the developing mouse reveals both a phenotypic and an anatomical division of direct pathway neurons, with striosomal direct pathway neurons having the greatest fluorescence. It has been suggested that the MSN population is composed of at least 5 putative subpopulations. These include direct pathway striosome neurons, indirect pathway striosome neurons, direct pathway matrix neurons and indirect pathway matrix neurons [1]. Cells co-expressing Drd1 and Drd2 or enkephalin and substance P $[2,16,78]$ may represent the fifth type. Nr4al-eGFP expression is most consistent with expression in direct pathway striosomal neurons but a small proportion of met-enkephalin expressing cells also express eGFP in vitro. Nr4al-eGFP expression and anatomical localization will be an additional tool to determine if functional differences exist between neuronal subtypes in each compartment.

The development of Nr4al expressing neurons parallels the development of Drd1 and essentially replicates previous studies on striatal development using other techniques. Developing striosomes contain TrkB, pERK, Drdl and are heavily innervated by dopaminergic fibers. Surprisingly, CREB phosphorylation did not correlate with eGFP expression in the developing striatum and cAMP is known to induce endogenous Nr4al [28]. CREB shows divergent regulation in the striosome vs. matrix. Sustained Drdl activation increased striosomal CREB phosphorylation while sustained calcium channel activation increased phosphorylation in the matrix in organotypic cultures indicating divergent regulation $[77,79,80]$. The transient nature of pCREB phosphorylation and differential regulation do not exclude CREB as a regulator of Nr4al-eGFP expression, as transcription factors work 

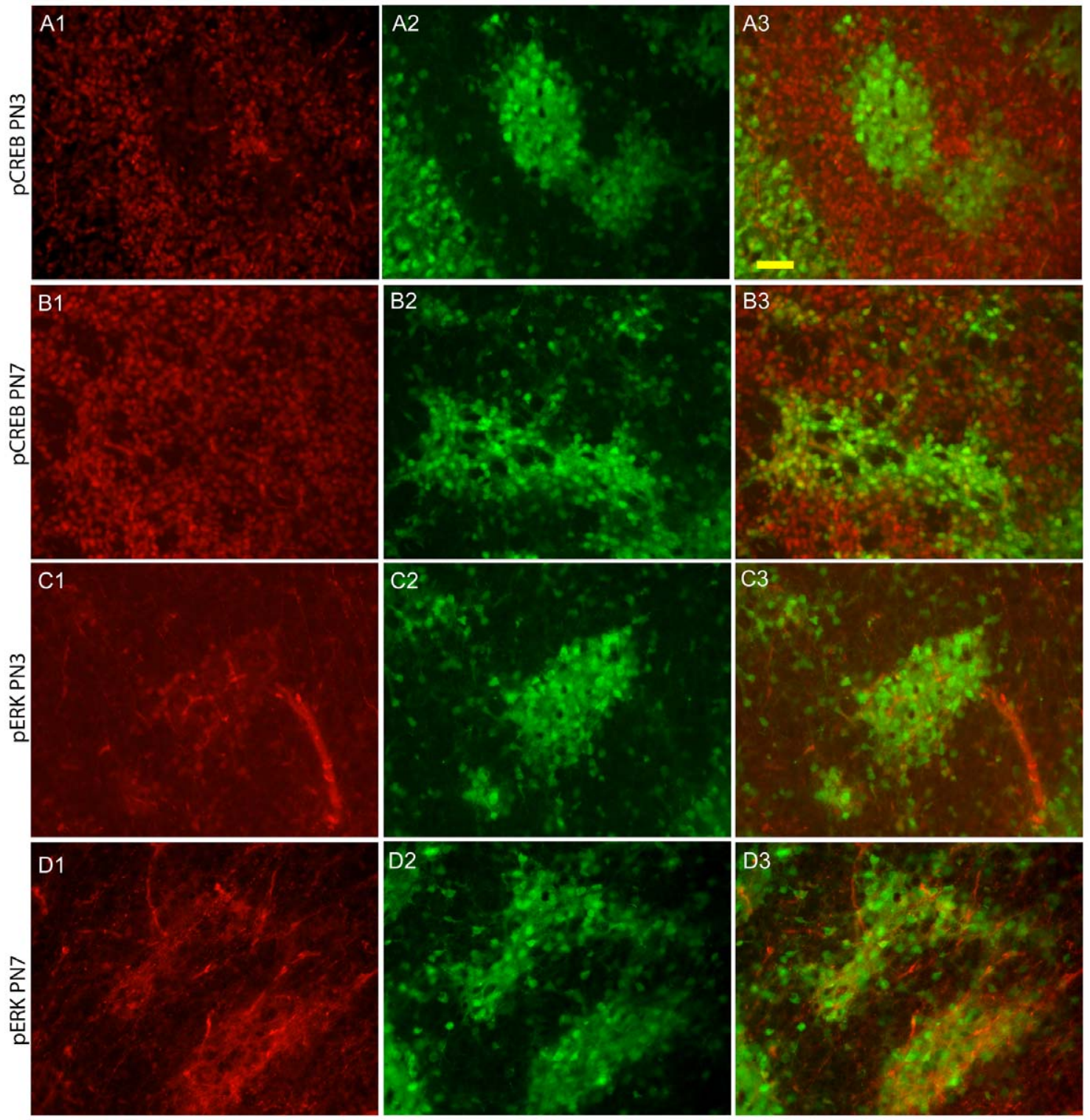

Figure 8. Phosphorylation of CREB and ERK in the neonatal Nr4a1-eGFP striatum. Phospho-CREB immunoreactivity is lower in the striosomes than in the surrounding matrix at PN3/4 (A1-A3) and PN7 (B1-B3). ERK phosphorylation shows the opposite pattern of immunoreactivity at both PN3/4 (C1-C3) but the distribution of pERK changes during development with nuclear and process localization at PN7 (C1 compared to D1). Nr4a1 and active ERK and CREB were also detected in the vasculature. Scale bar in A3 $(50 \mu \mathrm{m})$ applies to all images. doi:10.1371/journal.pone.0016619.g008

in a temporally concerted fashion to induce gene transcription. The lack of association between pCREB and eGFP expression postnatally (Fig. 9) and induction of Nr4al-eGFP by calcium and forskolin in vitro (Figs. 10 and 11) implies that Nr4al-eGFP expression may be actively repressed in matrix cells in vivo. Induction by forskolin in vitro suggests that the factors mediating repression can be over-ridden by a strong stimulus or may not be present in vitro (i.e. afferents).

Nr4al promoter-driven eGFP expression does not recapitulate endogenous $\mathrm{Nr} 4 \mathrm{al}$ protein expression in the mature mouse brain under basal conditions (Fig. $5 \mathrm{C}, \mathrm{D}$ ) or after induction in vitro (Fig. 11) in MSN cultures when measured by Western blot in total lysates. This is in contrast to colocalization in the developing brain (Fig. 5 A,B). The lack of colocalization of eGFP and Nr4al in the mature brain is likely due to numerous factors. First, the half life of the two mRNA species is different (Fig. 11). The endogenous mRNA is subject to $3^{\prime}$ regulation that is not present in the BAC construct and the mRNA for eGFP is further stabilized by a viral polyadenylation signal [64]. Second, the half lives of eGFP and Nr4al protein also differ (26 hrs [81] vs. $2-4$ hrs [36,63]). Finally, there appears to be a stable pool of Nr4al that does not associate with the nucleus (Figs. 5 and 11 and unpublished observations) and appears as a background at low power. However, when cultures were immunostained and examined microscopically we noted that the time course of nuclear localization in the brightly fluorescent cells was rapid, leaving the nucleus by $8 \mathrm{hrs}$. In contrast, perinuclear immunoreactivity for both $\mathrm{Nr} 4 \mathrm{al}$ and eGFP was observed after $8 \mathrm{hrs}$ in the dimly fluorescent cells, presumably corresponding to the matrix neurons. These data suggest that the strength or speed of induction may differ between striosomal cells 


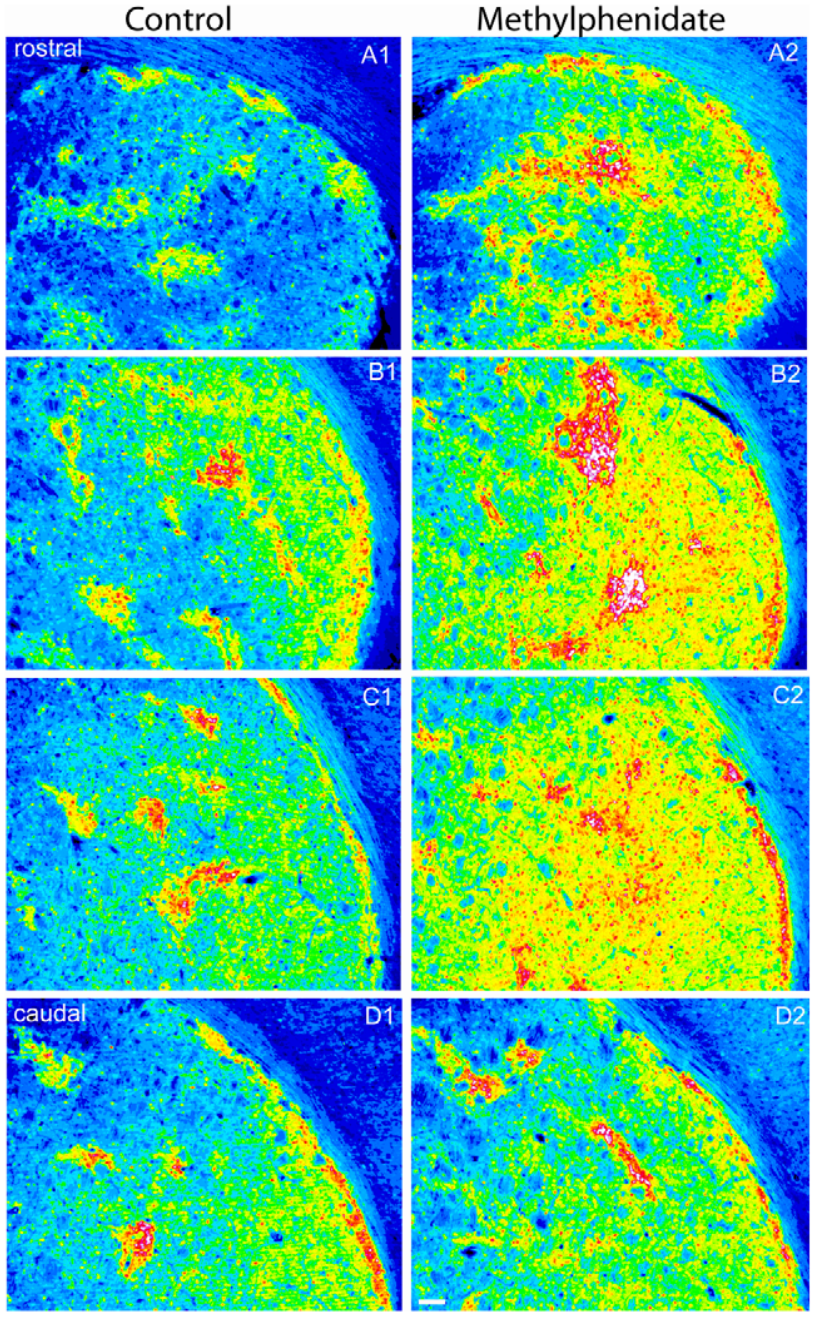

Figure 9. eGFP expression in mice administered $5 \mathrm{mg} / \mathrm{kg}$ of methylphenidate. Sections of similar striatal regions are shown for comparison. Images were pseudo-colored using image J (16-bit spectrum). Fluorescence intensity indicates increased levels in the more intense (striosomal, red) regions but also an increase in expression within the matrix (green to yellow shades). Scale bar is $100 \mu \mathrm{m}$. doi:10.1371/journal.pone.0016619.g009

and matrix cells. Consistent with this, Tian and colleagues [33] reported Nr4al induction in Drd2-expressing cells after $24 \mathrm{hrs}$ of exposure to high $\mathrm{KCl}$, while Heiman and colleagues [38] did not identify $\mathrm{Nr} 4 \mathrm{al}$ as a differentially regulated protein in direct vs. indirect pathway neurons by translational profiling of sorted Drdl and Drd2 cells. Combined, these data indicate that the difference between eGFP levels and native Nr4al levels reflect a dissociation in mRNA and protein regulation that differs between MSN populations.

Phosphorylated MEF2 represses Nr4al transcription and the calcium-activated phosphatase calcineurin is responsible for dephosphorylation of MEF2 [32,82]. Striatopallidal neurons show induction of endogenous $\mathrm{Nr} 4 \mathrm{al}$ in response to calcium channel activation in corticostriatal cocultures [33] and this is consistent with low expression in the matrix under basal conditions that is derepressed by synaptic activity through calcineurin [31,32,33,82]. Calcineurin is high in developing striosomes [83] therefore decreased striosomal pCREB [84] and increased Nr4al-eGFP may result through the same pathway, activity-dependent activation of calcineurin. These data do not exclude a role for cAMP and low levels of PCREB were present in the striosomes but implicate an activity-dependent MEF-like pathway as a gatekeeper. Divergent expression of endogenous $\mathrm{Nr} 4 \mathrm{al}$ and the eGFP reporter demonstrates complex regulation at the levels of translation, localization and degradation that should be considered when following eGFP reporter expression.

Induction of $\mathrm{Nr} 4 \mathrm{al}$ is associated with MSN synaptic remodeling [33] and high levels may therefore mark neurons undergoing plasticity in vivo after drug exposure or after various learning paradigms. Combined with fluorescence activated cell sorting, Nr4al-eGFP mice can be used to characterize the development and function of a subset of direct pathway neurons that are enriched and activated preferentially in striosomes. Nr4al-eGFP expression can be used to monitor the convergence of afferent pathways in vitro and in genetic mouse models such as cortexspecific deletion of BDNF or deletion of $\mathrm{TH}$. Activation of prefrontal circuits that preferentially project to the striosomes during behavioral paradigms that switch from goal directed to habitual behaviors or during reversal learning could lead to differential eGFP expression in striosome vs. matrix neurons. Optical monitoring of striosomal neurons in vivo is also feasible with this strain. In addition, variable expression between animals in the striatal-like regions of the amygdala indicates that the Nr4al-eGFP strain might be useful for identification of circuits involved in anxiety-like behavior. Three-dimensional serial reconstruction technologies have been developed to document complete pathways and connections. Adding the dimension of fluorescence intensity to the reconstruction algorithms would be a phenomenal advance in elucidating complex pathways regulating mouse behavior.

\section{Methods}

\section{Mice}

All animal procedures were carried out in accordance with the NIH Guide for the Care and Use of Laboratory Animals and were approved by the NIAAA animal care and use committee under protocol LIN-DL-21. All efforts were made to minimize suffering of animals. Transgenic Nr4al (Tg(Nr4al-EGFP139Gsat)), Drdl (Tg(Drd1-EGFP-X60Gsat)) and Drd2 (Tg(Drd2-EGFPS118Gsat)) were obtained from GENSAT and bred to SwissWebster mice (NIH). Experiments were performed on heterozygotes. Mice were genotyped at birth by fluorescence of the thymus, tails and ears using a hand held UV source.

\section{Staining Procedures}

Fixation. Adult mice were deeply anesthetized with isofluorane and transcardially perfused with $4 \%$ formaldehyde in phosphate-buffered saline (PBS). Neonatal mice were euthanized by rapid decapitation and brains were fixed in $4 \%$ formaldehyde for $24 \mathrm{hrs}$ at $4 \mathrm{C}$. Perfusion-fixed brains were post-fixed overnight in $4 \%$ formaldehyde. Neonatal brains were sectioned at $50 \mu \mathrm{m}$ and adult brains were sectioned at 40 or $50 \mu \mathrm{m}$ as indicated using a vibratome.

Immunofluorescence. Sections were blocked with 5\% bovine serum albumin in Phosphate-Buffered Saline, 0.02\% Triton X-100 (PBS-T) for $4 \mathrm{hrs}$ and then incubated in primary antibodies overnight at 4C. Antibodies used were as follows: chicken anti-GFP (Abcam, 1:2000), rabbit anti-calbindin (Millipore, 1:200), rabbit anti-calretinin (Millipore, 1:1000), rabbit anti-mu-opioid receptor (Immunostar, 1:5000), rat antiDrd1 (Sigma, 1:250), rabbit anti-Nur77 (Santa Cruz, 1:50) or chicken anti-TH (Abcam, 1:2000). Rabbit anti-GFP (Millipore, 

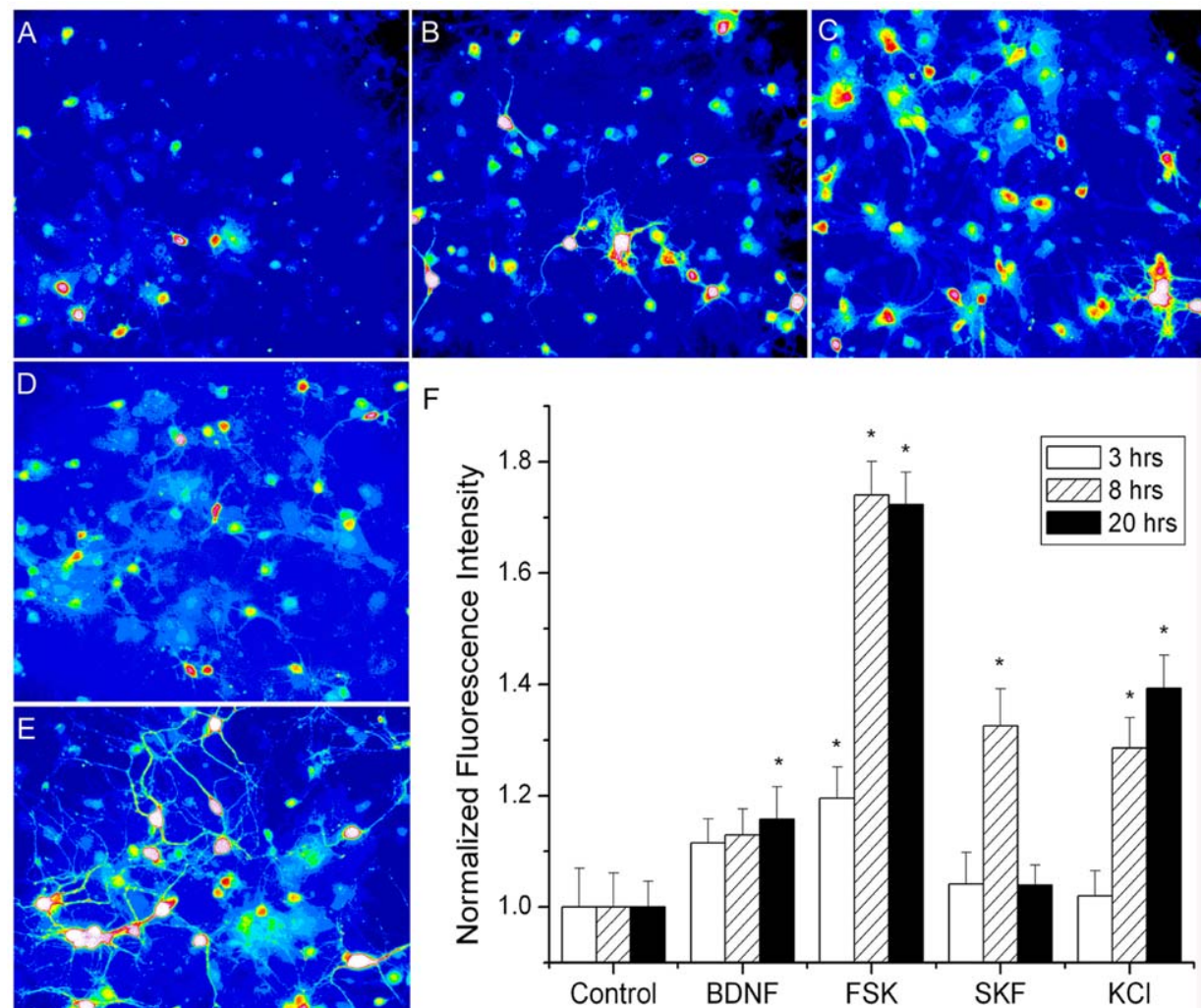

Figure 10. Native fluorescence and fluorometric detection of stimulated eGFP expression in primary cultures of medium spiny neurons stimulated in vitro. Pseudocolored images of control (A), $5 \mathrm{ng} / \mathrm{mL}$ BDNF (B), $1 \mu \mathrm{M}$ forskolin (C), $1 \mu \mathrm{M}$ SKF-83822 (D) or $30 \mathrm{mM}$ KCl (E) reveal eGFP induction after $20 \mathrm{hrs}$. eGFP expression was also measured fluorometrically in lysates at 3, 8 and 20 hrs after exposure (F). Native fluorescence is representative of 4 replicate fields taken at the same exposure time (set for linear detection in control cultures). Fluorometry data in $\mathrm{F}$ are the mean $+/-$ SE of 16 replicates for each time point and treatment. Data were analyzed by ANOVA ( $\left.{ }^{*} \mathrm{p}<0.05\right)$. Scale bar in $\mathrm{E}(20 \mu \mathrm{m})$ applies to all panels.

doi:10.1371/journal.pone.0016619.g010

1:200) was used for double labeling with TH. Following 3 washes in PBS-T, sections were incubated overnight in secondary antibodies. Alexa 488 goat anti-chicken (1:2000) and Alexa 568 goat anti-rabbit (1:1000) or Alexa 555 goat anti-rat (Drd1, 1:1000) were used in experiments except when in combination with chicken anti-TH where Alexa 568 goat anti-chicken (1:1000) and Alexa 488 goat anti-rabbit (1:200) were used (Invitrogen). All antibodies were well characterized and titrated to determine the optimal concentration. Control sections were treated as described with omission of the primary antiserum. Immunofluorescence on cell cultures was performed as described above on cells plated in 8well chamber slides, except the incubation times were shortened to $1 \mathrm{hr}$.

Counterstaining. Sections were then counterstained with DAPI (Invitrogen) in PBS $(0.25 \mathrm{ng} / \mathrm{mL})$, washed 3 times in PBS$\mathrm{T}$. Alexa-568 $\mathrm{IB}_{4}$ isolectin binding $(1 \mu \mathrm{g} / \mathrm{mL}$ in PBS-T, Invitrogen) was used for detection of the blood vessels (Fig. S2). Fifty micron sections were incubated overnight and washed three times as described above. Sections were mounted with Fluoromount G (Electron Microscopy Sciences) and sealed with nail polish.

Cell Culture. Primary cultures of MSNs were prepared from mice at 0-2 days of age. Striata were dissected on ice, minced and dissociated with papain prepared in MEM (Worthington, $20 \mathrm{U} /$ $\mathrm{mL}$ ) for $30 \mathrm{~min}$ at $30 \mathrm{C}$. Cells were centrifuged at $600 \mathrm{~g}$ and resuspended in MEM supplemented with glucose to $25 \mathrm{mM}, 2 \%$
B-27 supplement, $1 \mathrm{mM}$ sodium pyruvate, $1 \mathrm{mM}$ Glutamax, $100 \mathrm{U} / \mathrm{mL}$ penicillin, $100 \mu \mathrm{g} / \mathrm{mL}$ streptomycin, $5 \%$ fetal bovine serum and $0.5 \mu \mathrm{l} / \mathrm{mL}$ Mito Serum Extender. All cell culture media and supplements were from Invitrogen except for the fetal bovine serum (Hyclone) and Mito Serum Extender (BD Biosciences). Cells were grown on poly D-lysine coated culture plates (Costar) or 8-well chamber slides (Electron Microscopy Sciences). After 2 days in vitro, medium was changed to medium prepared as above but without serum. Cells were maintained at $37 \mathrm{C}, 5 \% \mathrm{CO}_{2}$ in a humidified incubator. Half of the medium was replaced every 3-4 days until assay at 7-10 DIV.

In Vitro EGFP Measurements. eGFP expression was analyzed as previously described [85]. Cells were treated with either $5 \mathrm{ng} / \mathrm{mL}$ BDNF, $1 \mu \mathrm{M}$ forskolin (Tocris), $1 \mu \mathrm{M}$ SKF83822. or $25 \mathrm{mM} \mathrm{KCl} \mathrm{(30} \mathrm{mM} \mathrm{final)} \mathrm{diluted} \mathrm{into} \mathrm{cell} \mathrm{culture}$ medium without serum or Mito Serum Extender. Control wells for forskolin and SKF-83822 contained a final concentration of $0.01 \%$ DMSO, although this did not change eGFP expression and control values were collapsed into a single group for analysis. After 3-20 hrs of incubation wells were lysed with $75 \mu \mathrm{L} 0.1 \%$ Triton $\mathrm{X}-100$ in PBS (with calcium and magnesium) and homogenized using an ELISA plate shaker. Fifty $\mu \mathrm{L}$ of homogenate was transferred to a black half-well plate and fluorescence was measured using a TECAN microplate fluorometer with the FITC filter set with the background (lysis buffer alone) subtracted. Data were normalized to the average of the control 

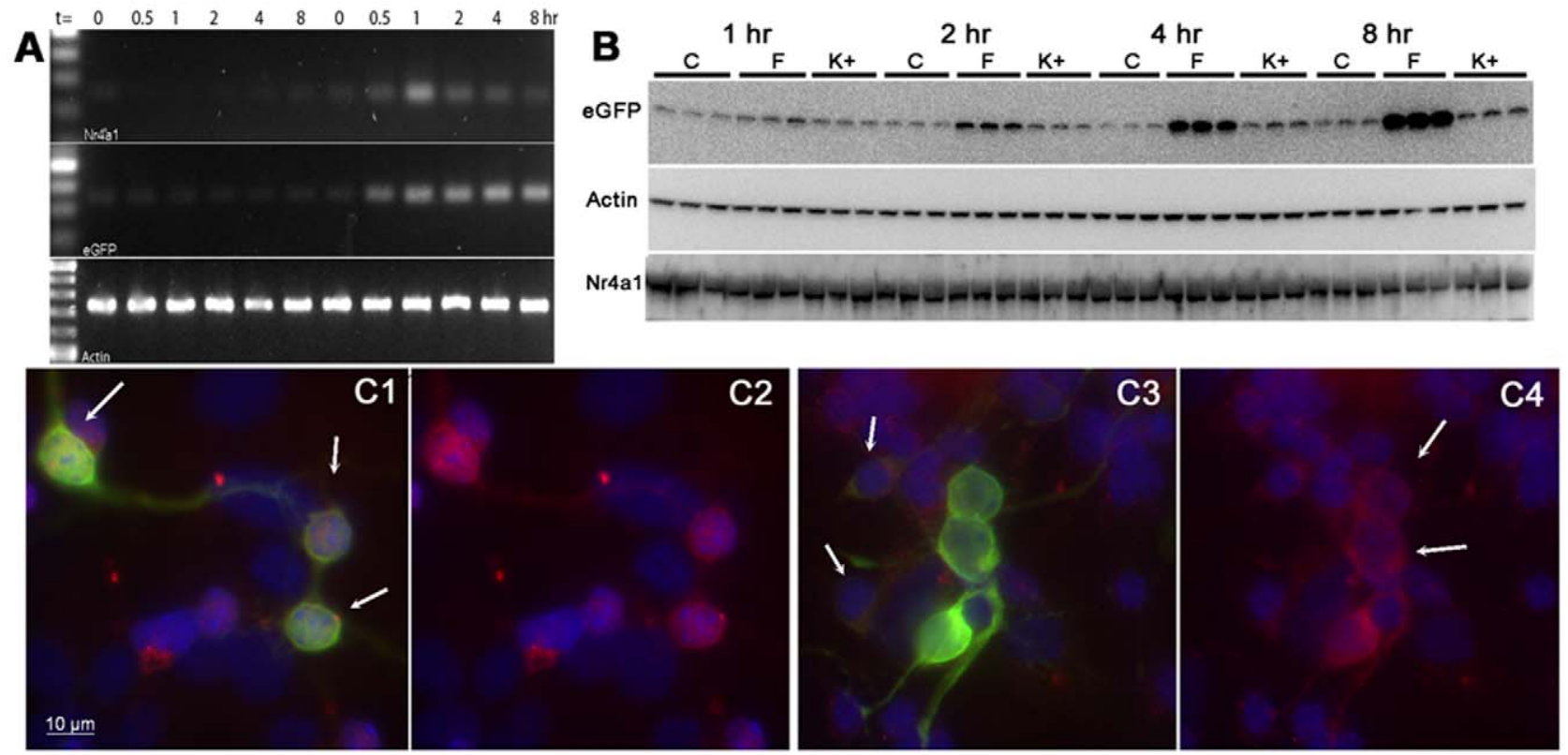

Figure 11. Time course for the in vitro induction of native Nr4a1 mRNA and protein compared to Nr4a1 promoter-driven eGFP expression in MSNs. Semi-quantitative PCR detection of Nr4a1, eGFP and actin mRNA after exposure to $30 \mathrm{mM} \mathrm{KCl}$ for $30 \mathrm{~min}$ to $8 \mathrm{hrs}$ is shown in A. Western blot detection of eGFP, Nr4a1 and actin induced by $30 \mathrm{mM} \mathrm{KCl}$ or forskolin ( $1 \mathrm{hr}$ to $8 \mathrm{hr}$ ) is shown in panel B. Immunofluorescent detection Nr4a1 (red) and eGFP in DAPI stained MSN cultures is shown in C1-C4 after 2 hrs of treatment with $30 \mathrm{mM} \mathrm{KCl}(\mathrm{C1}, \mathrm{C2})$ or 8 hrs (C3, C4). Arrows in C1 indicate nuclear expression in brightly fluorescent cells after $2 \mathrm{hrs}$ of exposure to $30 \mathrm{mM} \mathrm{KCl}$. DAPI and Nr4a1 are shown together in C2 for this time point. Cells treated for 8 hrs with $30 \mathrm{mM} \mathrm{KCl}$ are shown in C3,C4. Arrows (C3) indicate cells with perinuclear eGFP and Nr4a1 immunoreactivity. The DAPI and Nr4a1 channels are shown merged in C4. Arrows (C4) indicate the absence of Nr4a1 immunoreactivity in the nuclei of brightly eGFP-expressing cells at $8 \mathrm{hrs}$. Scale bar in C1 $(10 \mu \mathrm{m})$ applies to all images. doi:10.1371/journal.pone.0016619.g011

wells on each plate for each time point since B-27 and $30 \mathrm{mM}$ glucose (control) increased eGFP expression.

Electrophoresis and Western Blot. Nr4al was induced by media change even into formulations containing no additional growth factors so acute induction experiments were performed by treating with concentrated stocks at $5 \mathrm{X}$ in MEM with $5 \mathrm{mM}$ glucose, which did not result in significant Nr4al induction over the $30 \mathrm{~min}$ to $8 \mathrm{hr}$ time course. Cells were stimulated with $30 \mathrm{mM}$ $\mathrm{KCl}$ or $5 \mu \mathrm{M}$ forskolin (final) and lysed with $1 \%$ Triton $\mathrm{X}-100$ containing protease and phosphatase inhibitors (Sigma Mammalian Protease Inhibitor Cocktail and Phosphatase Inhibitor Cocktails 1 and 2). Lysates were sonicated, diluted with 2X Laemmli buffer containing $3 \%$ (v/v final) 2mercaptoethanol [86] and heated to $95 \mathrm{C}$ for $5 \mathrm{~min}$. Proteins were resolved on $11 \%$ SDS-polyacrylamide gels and transferred at $50 \mathrm{~mA}$ for $16 \mathrm{hrs}$ onto PVDF membranes according to the method of Towbin [87]. Blots were washed with Tris-Buffered Saline containing $0.05 \%$ Tween-20 (TTBS) and blocked with 5\% fat-free powdered milk in TTBS. Rabbit anti-Nr4al (Santa Cruz, 1:5000), mouse anti-GFP (Neuromab, 1:2000) or rabbit anti-B actin (Cell Signaling, 1:1000) were diluted in TTBS and incubated overnight at $4 \mathrm{C}$. Blots were washed and incubated for $1 \mathrm{hr}$ with HRP-conjugated anti-rabbit (Pierce, 1:20,000) or HRP-conjugated anti-mouse (Bio-Rad, 1:1000). Following a final series of washes, immunoreactivity was visualized using chemiluminescence (Pierce Super Signal Pico West) and imaged using a Kodak Image Station. The same blots were sequentially reprobed with each antibody.

Semi-quantitative RT-PGR. Cells were cultured in 48 well culture dishes and treated for $0-8 \mathrm{hrs}$ with $30 \mathrm{mM} \mathrm{KCl}$ as described above for protein expression. Cells were lysed in the culture dish wells by addition of $300 \mu \mathrm{L}$ of buffer RTL, a component of the RNeasy kit from Qiagen. Total RNA was isolated using this kit and $10 \mu \mathrm{L}$ of the resulting total RNA was reverse transcribed using the QuantiTect Reverse Transcription kit (Qiagen). The $20 \mu \mathrm{L}$ final reaction product was diluted to $120 \mu \mathrm{L}$ and $2 \mu \mathrm{L}$ of cDNA was transferred to one of 3 reaction tubes for amplification of Nr4al, eGFP or actin in $50 \mu \mathrm{L}$ reactions using 2X GoTaq Hot Start Polymerase Green Master Mix (Promega). Primer pairs (300 nM final reaction concentration) were $\left(5^{\prime}\right.$ to $\left.3^{\prime}\right)$ : mouse Nr4al (for GTCGGCACGTGTGAGGGCTGC, rev GGTAGGGGAGGCATGTGGAGGG): eGFP (for CGTAGGGGGTGCAGTGCTTGAGG, rev CGGGGAGCTGCACGCTGCGGTCGTC) and for mouse B-actin (for CTGAGGAGCACCCTGTGCTGC, rev CAAGGATGGAGGCACCGATCG). Seven $\mu \mathrm{L}$ aliquots of product were taken after 22,27 , and 37 cycles and $5 \mu \mathrm{L}$ of the aliquot was analyzed by $1.8 \%$ agarose gel electrophoresis. Bands were visualized using Syber-Safe (Invitrogen) and fluorescence captured using a Carestream Gel Logic 112 Imager.

Methylphenidate Exposure. Heterozygous mice were divided by litter and gender so that litter mates and cage mates of the same gender were used for comparison at each time point. Mice were injected at PN30 with $5 \mathrm{mg} / \mathrm{kg}$ methylphenidate in normal saline or vehicle and sacrificed $12 \mathrm{hrs}$ later. Brains were block fixed in cold $4 \%$ formaldehyde for $24 \mathrm{hrs}$ and processed within 1 week. Every 3rd section through the striatum was imaged and landmarks were used to insure imaging of similar striatal regions. eGFP antibody staining (above) was used in these experiments because of poor eGFP stability in stored tissue and the time required to section and image the brains.

Microscopy and Quantification of Immunofluorescence. Sections were imaged with a Zeiss Axiovert epifluorescence microscope or a Zeiss Lumar stereo-microscope equipped with standard DAPI, eGFP and Cy3 filter sets (Chroma). Images were 

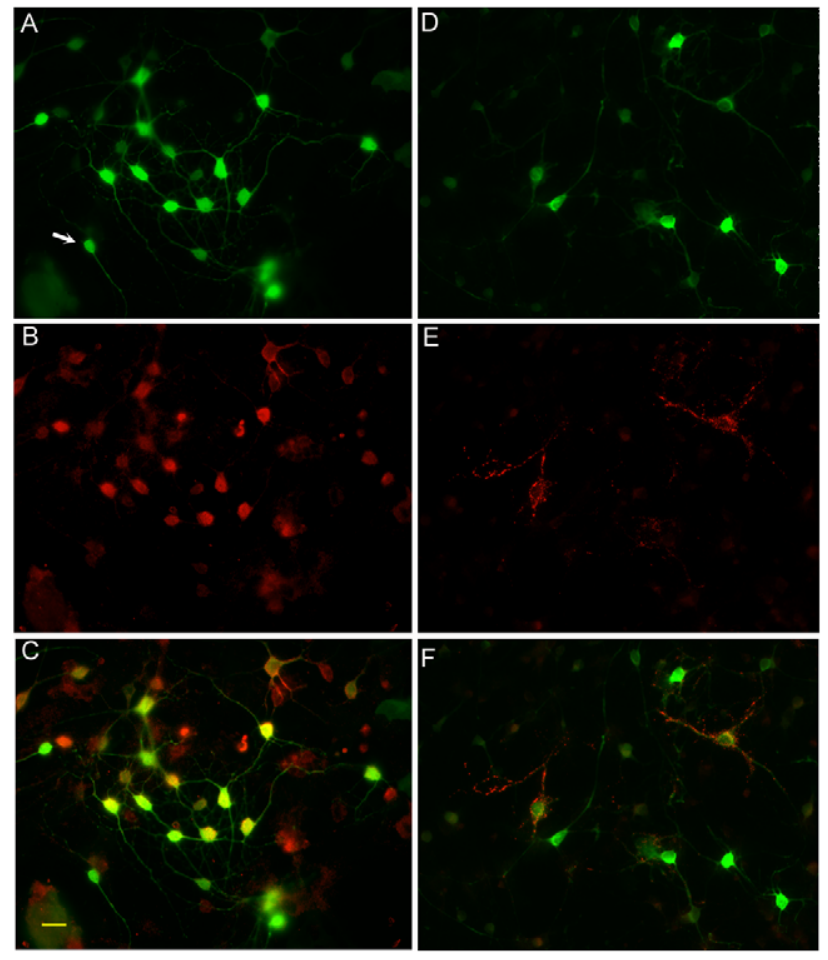

Figure 12. Immunodetection of Drd1, met-enkephalin and eGFP in cultured MSNs. eGFP (A) and Drd1 immunoreactivity (B) are shown merged in panel C. eGFP (D) and met-enkephalin (E) immunoreactivity was detected together in $\sim 15 \%$ of cells expressing high levels of eGFP (merge in F). Cells were treated for $12 \mathrm{hr}$ with $30 \mathrm{mM} \mathrm{KCl}$ prior to immunostaining. Scale bar in C $(20 \mu \mathrm{m})$ and applies to all images.

doi:10.1371/journal.pone.0016619.g012

captured with an Axiocam MR using the Axiovision software. For some figures binary images were converted to pseudo-colored images using Image J (Scion Corp.) for presentation as indicated in the figure legends using the 16-bit spectrum lookup tables. Images were collected using the same exposure times and background subtractions (when used) were linear and the same for all sections within each experiment when quantitative comparisons were made.

\section{References}

1. Kawaguchi Y (1997) Neostriatal cell subtypes and their functional roles. Neurosci Res 27: 1-8.

2. Valjent E, Bertran-Gonzalez J, Hervé D, Fisone G, Girault J-A (2009) Looking $\mathrm{BAC}$ at striatal signaling: cell-specific analysis in new transgenic mice. Trends Neurosci 32: 538-547.

3. Voorn P, Vanderschuren LJMJ, Groenewegen HJ, Robbins TW, Pennartz CMA (2004) Putting a spin on the dorsal-ventral divide of the striatum. Trends Neurosci 27: 468-474.

4. Berretta S, Parthasarathy HB, Graybiel AM (1997) Local Release of GABAergic Inhibition in the Motor Cortex Induces Immediate-Early Gene Expression in Indirect Pathway Neurons of the Striatum. J Neurosci 17: 4752-4763.

5. Lawhorn C, Smith DM, Brown LL (2009) Partial ablation of mu-opioid receptor rich striosomes produces deficits on a motor-skill learning task. Neuroscience 163: 109-119.

6. White NM, Hiroi N (1998) Preferential localization of self-stimulation sites in striosomes/patches in the rat striatum. Proc Natl Acad Sci U S A 95: 6486-6491.

7. Gerfen CR (1992) The neostriatal mosaic: multiple levels of compartmental organization. Trends Neurosci 15: 133-139.

8. Canales JJ (2005) Stimulant-induced adaptations in neostriatal matrix and striosome systems: Transiting from instrumental responding to habitual behavior in drug addiction. Neurobiology Learn Mem 83: 93-103.

9. Joel D, Weiner I (2000) The connections of the dopaminergic system with the striatum in rats and primates: an analysis with respect to the functional and compartmental organization of the striatum. Neuroscience 96: 451-474.

\section{Supporting Information}

Figure S1 Nr4a1-eGFP expression within the central nervous system in the adult mouse. Diffuse expression was observed throughout the brain in fibers and somata. Panels are labeled with the approximate location relative to Bregma according to the Allen Brain Atlas coordinates for an adult C57/Bl6J mouse and are therefore approximate. The predominant structure in each panel is indicated. Abbreviations: Olf, oflactory; PrL, prelimbic cortex, Pir, piriform cortex; M1/M2, motor cortex 1/2; Hab, habenula; MeA, medial amygdala; Hyp, hypothalamus; $\mathrm{Au} \mathrm{Cx}$, auditory cortex; LGN, lateral geniculate nucleus; HP, hippocampus; vHP, ventral hippocampus; PAG, periaquiductal grey; Coll, colliculi; CB, cerebellum. Panels are of the left hemisphere except for medial regions (B3, C1, E1).

(TIF)

Figure S2 Gross survey of peripheral expression of Nr4a1-eGFP. eGFP fluorescence was detected in the intestine (A), muscle and spinal ganglia $(\mathrm{B})$, heart $(\mathrm{C})$, spleen $(\mathrm{D})$, testes $(\mathrm{E}$, higher magnification, $\left.\mathrm{E}^{\prime}\right)$ and lung $(\mathrm{F})$. eGFP in the liver $(\mathrm{G})$ was primarily associated with the vasculature $\left(G^{\prime}\right.$ stained with $\mathrm{IB}_{4}$ isolectin). Expression in the kidney $(\mathrm{H})$ was also associated with the vasculature (higher power shown in $\mathrm{I}$, Alexa-568 $\mathrm{IB}_{4}$ isolectin binding is shown in $\left.\mathrm{I}^{\prime}\right)$. Images were taken with a Zeiss Lumar stereomicroscope (A, B, E, F, H) or a Zeiss Axiovert epifluorescence microscope $\left(\mathrm{D}, \mathrm{E}^{\prime}, \mathrm{G}, \mathrm{G}^{\prime}, \mathrm{I}^{\prime} \mathrm{I}^{\prime}\right)$. Scale bars are present in each panel.

(TIF)

\section{Acknowledgments}

We would like to thank David Lovinger for helpful discussions and critical review of this manuscript. We also thank Yolanda Mateo for injecting mice, Verginia Cuzon Carlson for perfusing mice and Ross Carpenter for assistance collecting and sectioning peripheral organs. We are grateful to the staff at the Fisher's Lane Animal Facility for their excellent animal husbandry.

\section{Author Contributions}

Conceived and designed the experiments: MID. Performed the experiments: MID HLP. Analyzed the data: MID HLP. Wrote the paper: MID.

10. Donoghue JP, Herkenham M (1986) Neostriatal projections from individual cortical fields conform to histochemically distinct striatal compartments in the rat. Brain Res 365: 397-403.

11. Ebrahimi A, Pochet R, Roger M (1992) Topographical organization of the projections from physiologically identified areas of the motor cortex to the striatum in the rat. Neurosci Res 14: 39-60.

12. Fujiyama F, Unzai T, Nakamura K, Nomura S, Kaneko T (2006) Difference in organization of corticostriatal and thalamostriatal synapses between patch and matrix compartments of rat neostriatum. Eur J Neurosci 24: 28132824.

13. Snyder-Keller AM (1991) Development of striatal compartmentalization following pre- or postnatal dopamine depletion. J Neurosci 11: 810-821.

14. Zahm DS (1991) Compartments in rat dorsal and ventral striatum revealed following injection of 6-hydroxydopamine into the ventral mesencephalon. Brain Res 552: 164-169.

15. Xu M, Moratalla R, Gold LH, Hiroi N, Koob GF, et al. (1994) Dopamine D1 receptor mutant mice are deficient in striatal expression of dynorphin and in dopamine-mediated behavioral responses. Cell 79: 729-742.

16. Penny GR, Afsharpour S, Kitai ST (1986) The glutamate decarboxylase-, leucine enkephalin-, methionine enkephalin-and substance P-immunoreactive neurons in the neostriatum of the rat and cat: Evidence for partial population overlap. Neuroscience 17: 1011-1045.

17. Edley SM, Herkenham M (1984) Comparative development of striatal opiate receptors and dopamine revealed by autoradiography and histofluorescence. Brain Res 305: 27-42. 
18. Olson L, Seiger Å, Fuxe K (1972) Heterogeneity of striatal and limbic dopamine innervation: Highly fluorescent islands in developing and adult rats. Brain Res 44: 283-288.

19. Pert G, Kuhar M, Snyder S (1976) Opiate receptor: autoradiographic localization in rat brain. Proc Natl Acad Sci U S A 73: 3729-3733.

20. Bowen WD GS, Herkenham M, Pert CB (1981) Interconverting mu and delta forms of the opiate receptor in rat striatal patches. Proc Natl Acad Sci U S A 78: 4818-4822.

21. Tempel A, Zukin R (1987) Neuroanatomical patterns of the mu, delta, and kappa opioid receptors of rat brain as determined by quantitative in vitro autoradiography. Proc Natl Acad Sci U S A 84: 4308-4312.

22. Wang H, Moriwaki A, Wang JB, Uhl GR, Pickel VM (1996) Ultrastructural immunocytochemical localization of $\mu$ opioid receptors and Leu5-enkephalin in the patch compartment of the rat caudate-putamen nucleus. J Comp Neurol 375: 659-674.

23. Graybiel AM, Ragsdale CW, Jr. (1978) Histochemically distinct compartments in the striatum of human, monkeys, and cat demonstrated by acetylthiocholinesterase staining. Proc Natl Acad Sci U S A 75: 5723-5726.

24. Kaneko T, Minami M, Satoh M, Mizuno N (1995) Immunocytochemical localization of $[\mathrm{mu}]$-opioid receptor in the rat caudate-putamen. Neurosci Lett 184: 149-152.

25. Koshimizu Y, Wu SX, Unzai T, Hioki H, Sonomura T, et al. (2008) Paucity of enkephalin production in neostriatal striosomal neurons: analysis with preproenkephalin-green fluorescent protein transgenic mice. Eur J Neurosci 28: 2053-2064.

26. Miura M, Saino-Saito S, Masuda M, Kobayashi K, Aosaki T (2007) Compartment-Specific Modulation of GABAergic Synaptic Transmission by mu-Opioid Receptor in the Mouse Striatum with Green Fluorescent ProteinExpressing Dopamine Islands. J Neurosci 27: 9721-9728.

27. Barth AL (2007) Visualizing circuits and systems using transgenic reporters of neural activity. Curr Opin Neurobiol 17: 567-571.

28. Pearen MA, Muscat GE (2010) Minireview: Nuclear Hormone Receptor 4A Signaling: Implications for Metabolic Disease. Mol Endocrinol. 24: 1891-1903.

29. Bondy GP (1991) Phorbol ester, forskolin, and serum induction of a human colon nuclear hormone receptor gene related to the NUR 77/NGFI-B genes. Cell Growth Differ 2: 203-208.

30. Bourhis E, Maheux J, Paquet B, Kagechika H, Shudo K, et al. (2009) The transcription factors Nur77 and retinoid X receptors participate in amphetamine-induced locomotor activities. Psychopharmacology (Berl) 202: 635-648.

31. Lam BY, Zhang W, Ng DC, Maruthappu M, Roderick HL, et al. (2010) CREBdependent Nur77 induction following depolarization in PC12 cells and neurons is modulated by MEF2 transcription factors. J Neurochem 112: 1065-1073.

32. Lam BYH, Zhang W, Enticknap N, Haggis E, Cader MZ, et al. (2009) Inverse Regulation of Plasticity-related Immediate Early Genes by Calcineurin in Hippocampal Neurons. J Biol Chem 284: 12562-12571.

33. Tian X, Kai L, Hockberger PE, Wokosin DL, Surmeier DJ (2010) MEF-2 regulates activity-dependent spine loss in striatopallidal medium spiny neurons. Mol Cell Neurosci 44: 94-108.

34. Han YH, Cao X, Lin B, Lin F, Kolluri SK, et al. (2006) Regulation of Nur77 nuclear export by c-Jun N-terminal kinase and Akt. Oncogene 25: 2974-2986.

35. Katagiri Y, Takeda K, Yu Z-X, Ferrans VJ, Ozato K, et al. (2000) Modulation of retinoid signalling through NGF-induced nuclear export of NGFI-B. Nat Cell Biol 2: 435-440.

36. No H, Bang Y, Lim J, Kim SS, Choi H-S, et al. (2010) Involvement of induction and mitochondrial targeting of orphan nuclear receptor Nur77 in 6-OHDAinduced SH-SY5Y cell death. Neurochem Int 56: 620-626.

37. Lobo MK, Karsten SL, Gray M, Geschwind DH, Yang XW (2006) FACS-array profiling of striatal projection neuron subtypes in juvenile and adult mouse brains. Nat Neurosci 9: 443-452.

38. Heiman M, Schaefer A, Gong S, Peterson JD, Day M, et al. (2008) A Translational Profiling Approach for the Molecular Characterization of CNS Cell Types. Cell 135: 738-748.

39. Backman C, Morales M (2002) Acute methamphetamine administration upregulates NGFI-B mRNA expression in the striatum: co-localization with cFos immunoreactivity. Synapse 44: 158-165.

40. Lynch WJ, Girgenti MJ, Breslin FJ, Newton SS, Taylor JR (2008) Gene profiling the response to repeated cocaine self-administration in dorsal striatum: A focus on circadian genes. Brain Res 1213: 166-177.

41. Akivama K, Isao T, Ide S, Ishikawa M, Saito A (2008) mRNA expression of the Nurrl and NGFI-B nuclear receptor families following acute and chronic administration of methamphetamine. Prog Neuro-Psychopharmacol Biol Psych 32: 1957-1966.

42. Werme M, Olson L, Brené S (2000) NGFI-B and Nor1 mRNAs are upregulated in brain reward pathways by drugs of abuse: different effects in Fischer and Lewis rats. Mol Brain Res 76: 18-24.

43. Ammon S, Mayer P, Riechert U, Tischmeyer H, Höllt V (2003) Microarray analysis of genes expressed in the frontal cortex of rats chronically treated with morphine and after naloxone precipitated withdrawal. Mol Brain Res 112: $113-125$.

44. Maheux J, Ethier I, Rouillard C, Levesque D (2005) Induction Patterns of Transcription Factors of the Nur Family (Nurr1, Nur77, and Nor-1) by Typical and Atypical Antipsychotics in the Mouse Brain: Implication for Their Mechanism of Action. J Pharmacol Exp Ther 313: 460-473.
45. Matamales M, Bertran-Gonzalez J, Salomon L, Degos B, Deniau JM, et al. (2009) Striatal medium-sized spiny neurons: identification by nuclear staining and study of neuronal subpopulations in BAC transgenic mice. PLoS One 4: e4770.

46. Lévesque M, Bédard A, Cossette M, Parent A (2003) Novel aspects of the chemical anatomy of the striatum and its efferents projections. J Chem Neuroanat 26: 271-281.

47. Desban M, Kemel ML, Glowinski J, Gauchy C (1993) Spatial organization of patch and matrix compartments in the rat striatum. Neuroscience 57: 661-671.

48. Berendse HW, Galis-de Graaf Y, Groenewegen HJ (1992) Topographical organization and relationship with ventral striatal compartments of prefrontal corticostriatal projections in the rat. J Comp Neurol 316: 314-347.

49. Breuer O, Lawhorn C, Miller T, Smith DM, Brown LL (2005) Functional architecture of the mammalian striatum: Mouse vascular and striosome organization and their anatomic relationships. Neurosci Lett 385: 198-203.

50. Gerfen CR (1985) The neostriatal mosaic. I. Compartmental organization of projections from the striatum to the substantia nigra in the rat. J Comp Neurol 236: 454-476.

51. Liu FC, Graybiel AM (1992) Heterogeneous development of calbindin-D28K expression in the striatal matrix. J Comp Neurol 320: 304-322.

52. Gerfen CR, Baimbridge KG, Thibault J (1987) The neostriatal mosaic: III. Biochemical and developmental dissociation of patch-matrix mesostriatal systems. J Neurosci 7: 3935-3944.

53. Seifert U, Härtig W, Grosche J, Brückner G, Riedel A, et al. (1998) Axonal expression sites of tyrosine hydroxylase, calretinin- and calbindin-immunoreactivity in striato-pallidal and septal nuclei of the rat brain: a doubleimmunolabelling study. Brain Res 795: 227-246.

54. Bubser M, Scruggs JL, Young CD, Deutch AY (2000) The distribution and origin of the calretinin-containing innervation of the nucleus accumbens of the rat. Eur J Neurosci 12: 1591-1598.

55. Härtig W, Riedel A, Grosche J, Edwards RH, Fremeau RT, et al. (2003) Complementary distribution of vesicular glutamate transporters 1 and 2 in the nucleus accumbens of rat: Relationship to calretinin-containing extrinsic innervation and calbindin-immunoreactive neurons. J Comp Neurol 465: 1-10.

56. Voorn P, Gerfen CR, Groenewegen HJ (1989) Compartmental organization of the ventral striatum of the rat: immunohistochemical distribution of enkephalin, substance P, dopamine, and calcium-binding protein. J Comp Neurol 289: 189-201.

57. Jongen-R???lo AL, Groenewegen HJ, Voorn P (1993) Evidence for a multicompartmental histochemical organization of the nucleus accumbens in the rat. J Comp Neurol 337: 267-276.

58. Millhouse OE (1986) The intercalated cells of the amygdala. J Comp Neurol 247: $246-271$

59. Kaoru T, Liu FC, Ishida M, Oishi T, Hayashi M, et al. (2010) Molecular characterization of the intercalated cell masses of the amygdala: implications for the relationship with the striatum. Neuroscience 166: 220-230.

60. Waclaw RR, Ehrman LA, Pierani A, Campbell K (2010) Developmental origin of the neuronal subtypes that comprise the amygdalar fear circuit in the mouse. J Neurosci 30: 6944-6953.

61. Likhtik E, Popa D, Apergis-Schoute J, Fidacaro GA, Pare D (2008) Amygdala intercalated neurons are required for expression of fear extinction. Nature 454: $642-645$.

62. Fuxe K, Jacobsen KX, Höistad M, Tinner B, Jansson A, et al. (2003) The dopamine D1 receptor-rich main and paracapsular intercalated nerve cell groups of the rat amygdala: relationship to the dopamine innervation. Neuroscience 119: 733-746.

63. Kang S-A, Na H, Kang H-J, Kim S-H, Lee M-H, et al. Regulation of Nur77 protein turnover through acetylation and deacetylation induced by $\mathrm{p} 300$ and HDAC1. Biochem Pharmacol 80: 867-873.

64. Gong S, Zheng C, Doughty ML, Losos K, Didkovsky N, et al. (2003) A gene expression atlas of the central nervous system based on bacterial artificial chromosomes. Nature 425: 917-925.

65. Graybiel AM (1984) Correspondence between the dopamine islands and striosomes of the mammalian striatum. Neuroscience 13: 1157-1187.

66. Murrin LC, Ferrer JR (1984) Ontogeny of the rat striatum: Correspondence of dopamine terminals, opiate receptors and acetylcholinesterase. Neurosci Lett 47: $155-160$.

67. Caille I, Dumartin B, Moine CL, Begueret J, Bloch B (1995) Ontogeny of the D1 Dopamine Receptor in the Rat Striatonigral System: an lmmunohistochemical Study. Eur J Neurosci 7: 714-722.

68. Rao PA, Molinoff PB, Joyce JN (1991) Ontogeny of dopamine D1 and D2 receptor subtypes in rat basal ganglia: a quantitative autoradiographic study. Dev Brain Res 60: 161-177.

69. Fishell G, van der Kooy D (1987) Pattern formation in the striatum: developmental changes in the distribution of striatonigral neurons. J Neurosci 7: 1969-1978.

70. Specht LA, Pickel VM, Joh TH, Reis DJ (1981) Light-microscopic immunocytochemical localization of tyrosine hydroxylase in prenatal rat brain. II. Late ontogeny. J Comp Neurol 199: 255-276.

71. Costantini LC, Feinstein SC, Radeke MJ, Snyder-Keller A (1999) Compartmental expression of trkB receptor protein in the developing striatum. Neuroscience 89: 505-513. 
72. Altar CA, Cai N, Bliven T, Juhasz M, Conner JM, et al. (1997) Anterograde transport of brain-derived neurotrophic factor and its role in the brain. Nature 389: 856-860.

73. Capper-Loup C, Canales JJ, Kadaba N, Graybiel AM (2002) Concurrent Activation of Dopamine D1 and D2 Receptors Is Required to Evoke Neural and Behavioral Phenotypes of Cocaine Sensitization. J Neurosci 22: 6218-6227.

74. Graybiel A, Mortalla R, Robertson H (1990) Amphetamine and cocaine induce drug-specific activation of the striatum. Proc Natl Acad Sci U S A 87: 6912-6916.

75. Tan A, Moratalla R, Lyford GL, Worley P, Graybiel AM (2000) The ActivityRegulated Cytoskeletal-Associated Protein Arc Is Expressed in Different Striosome-Matrix Patterns Following Exposure to Amphetamine and Cocaine. J Neurochem 74: 2074-2078.

76. Wang JQ, McGinty JF (1996) Acute methamphetamine-induced zif/268, preprodynorphin, and preproenkephalin mRNA expression in rat striatum depends on activation of NMDA and kainate/AMPA receptors. Brain Res Bull 39: 349-357.

77. Liu F, Graybiel AM (1998) Activity-regulated phosphorylation of cAMP response element binding protein in the developing striatum: implications for patterning the neurochemical phenotypes of striatal compartments. Dev Neurosci 20: 229-236.

78. Wang HB, Deng YP, Reiner A (2007) In situ hybridization histochemical and immunohistochemical evidence that striatal projection neurons co-containing substance $\mathrm{P}$ and enkephalin are overrepresented in the striosomal compartment of striatum in rats. Neurosci Lett 425: 195-199.
79. Liu FC, Takahashi H, McKay RD, Graybiel AM (1995) Dopaminergic regulation of transcription factor expression in organotypic cultures of developing striatum. J Neurosci 15: 2367-2384.

80. Liu FC, Graybiel AM (1996) Spatiotemporal dynamics of CREB phosphorylation: transient versus sustained phosphorylation in the developing striatum. Neuron 17: 1133-1144.

81. Corish P, Tyler-Smith C (1999) Attenuation of green fluorescent protein half-life in mammalian cells. Protein Eng 12: 1035-1040.

82. Flavell SW, Cowan CW, Kim T-K, Greer PL, Lin Y, et al. (2006) ActivityDependent Regulation of MEF2 Transcription Factors Suppresses Excitatory Synapse Number. Science 311: 1008-1012.

83. Goto S, Hirano A (1989) Calcineurin in the postnatal striatum of the rat: an immunohistochemical study. Exp Brain Res 77: 442-446.

84. Liu FG, Graybiel AM (1998) Activity-Regulated Phosphorylation of cAMP Response Element Binding Protein in the Developing Striatum: Implications for Patterning the Neurochemical Phenotypes of Striatal Compartments. Dev Neurosci 20: 229-236.

85. Hassoun AT, Erdélyi F, Szabó G, Davis MI (2007) A rapid screening method for population-specific neuronal motogens, substrates and associated signaling pathways. Journal of Neurosci Meth 166: 178-194.

86. Laemmli UK (1970) Cleavage of structural proteins during the assembly of the head of bacteriophage T4. Nature 227: 680-685.

87. Towbin H, Staehelin T, Gordon J (1979) Electrophoretic transfer of proteins from polyacrylamide gels to nitrocellulose sheets: procedure and some applications. Proc Natl Acad Sci U S A 76: 4350-4354. 